\title{
Public Health Events Emergency Management Supervision Strategy Considering New Media and Citizen Participation
}

Bingjie Lu

Shandong Normal University

Lilong Zhu ( $\nabla$ zhulilong2008@126.com )

Shandong Normal University https://orcid.org/0000-0002-9697-3012

\section{Research Article}

Keywords: Public health events, Emergency management, Supervision strategy, Evolutionary game, Simulation analysis

Posted Date: January 11th, 2022

DOI: https://doi.org/10.21203/rs.3.rs-847799/v1

License: (c) (i) This work is licensed under a Creative Commons Attribution 4.0 International License. Read Full License 


\title{
Title Page
}

\section{Public Health Events Emergency Management Supervision}

\section{Strategy Considering New Media and Citizen Participation}

\author{
Bingjie LU ${ }^{1,2}$, Lilong $\mathrm{Zhu}^{1,2 *}$ \\ ${ }^{1}$ School of Business, Shandong Normal University, Ji'nan, 250014, China \\ ${ }^{2}$ Quality Research Center, Shandong Normal University, Ji’nan, 250014, China \\ * Corresponding author. \\ E-mail: zhulilong@sdnu.edu.cn. Tel: +86-13853193366 \\ Lilong Zhu, Ph.D. and Professor \\ Postdoctoral research in Shandong University, Ph.D. degree was granted in \\ management science and engineering in Tongji University, Research scholar in \\ College of Business, University of Illinois at Urbana-Champaign, USA, Visiting \\ scholar in Tsinghua University, China. His research interests are product quality \\ management in supply chain.
}

\section{Acknowledgments}

The authors are grateful to the referees for their valuable comments and their helps on how to improve the quality of our paper. This work was supported by the National Social Science Foundation of China under grant No.20BGL272 and No.21ZDA024.

\section{Statistical data}

All the data is available and within the manuscript, no supplement materials data.

Competing interests

The authors declare that no competing interests exist.

Short title

Public Health Events Emergency Management Supervision Strategy

Total word count

9310 words, 40 pages, 4 tables, 10 figures. 


\title{
Public Health Events Emergency Management Supervision Strategy Considering New Media and Citizen Participation
}

\begin{abstract}
Public health events endanger the citizen health, economic development, social stability and national security seriously. Emergency management requires the joint participation of multiple parties. Therefore, we construct an evolutionary game model involving government department, pharmaceutical enterprises, citizens and new media, analyze the evolutionary stability, solve the stable equilibrium points using the Lyapunov first method and conduct the simulation analysis with Matlab 2020b. The results show that, firstly, the greater the probability of citizens making true evaluation, the more inclined the government department is to strictly implement the emergency management system, and when true evaluation causes the government department to bear more punishment, the probability that the government department doesn't strictly implement is smaller; secondly, when the probability of citizens making true evaluation decreases, new media are more inclined to report after verification, and when new media lose more pageview value or should be punished more for reporting without verification, the probability that they report without verification is smaller; thirdly, the greater the probability of citizens making false evaluation, the less enthusiasm of pharmaceutical enterprises to participate in emergency management, which indicates that false evaluation is detrimental to prompt pharmaceutical enterprises to participate; what's more, the greater the probability of new media reporting after verification, the greater the probability of pharmaceutical enterprises actively participating, which shows that new media's verification to citizens' evaluation is beneficial to emergency management. So, this paper provides suggestions for the emergency management and supervision.
\end{abstract}

Keywords: Public health events; Emergency management; Supervision strategy; Evolutionary game; Simulation analysis 


\section{Introduction}

In recent years, public health events have occurred frequently around the world, such as SARS in 2003, Influenza A (H1N1) in 2009, Middle East Respiratory Syndrome in 2012, Ebola virus in 2014, Zika virus in 2016 and COVID-19 in late 2019. The outbreak and spread of public health events have seriously endangered the citizen health, economic development, social stability and national security. How to conduct the emergency management has become an urgent problem to be solved in every country and region.

To deal with public health events, the World Health Organization(WHO) has published Framework for a Public Health Emergency Operations Centre, which provides high-level methodological guidance for the design, development and strengthening of public health emergency management agencies in order to achieve a "goal-oriented" response. In the United States, Metropolitan Medical Response System(MMRS) is an important system in the emergency management of public health events. According to the needs of the Federal Ministry of Health, local governments have set up the emergency committees, established the sound infectious disease notification system and complete medical response system. The European Union has established the Early Warning and Emergency Response System (EWRS) and the European Centre for Disease Prevention and Control (ECDC), which form the emergency management system for infectious diseases. Among them, Germany established the STAKOB (Center for Capacity and Treatment of Serious Infectious Diseases) to assess, investigate and respond to public health events. Australia has built an emergency management system at the federal government, state and local governments and community levels, and issued the National Health Emergency Response Arrangement, which outlines the executive departments, responsibility and arrangements for public health events to strengthen the monitoring mechanism and emergency management system. Japan has used advanced science and technology to monitor potential risks of public health events, and further improved the timeliness and accuracy of emergency information through information sharing platform. China has established the State Bureau for Disease Control and Prevention, which is responsible for formulating policies on the prevention and control of infectious diseases and public health supervision, planning the construction of the monitoring and early warning system for public health events, and guiding public health 
supervision and management.

To sum up, government department plays a leading role in the emergency management of public health events and is responsible for establishing and improving the emergency management system. However, public health events are highly professional, and the basis of emergency management is the scientific allocation and strong guarantee of drugs, vaccines and other supplies, which require the active participation of pharmaceutical enterprises. In addition, with the rapid development of the Internet, new media have the strong ability to collect and disseminate information. As the main body of public opinion supervision, the citizens can feed back their own information to new media, and exert public opinion influence on government department and pharmaceutical enterprises through new media's report.

Therefore, we consider new media and citizen participation, and construct an evolutionary game model involving the government department, pharmaceutical enterprises, citizens and new media. The stable equilibrium points of each game player's strategy choices are solved. The evolutionary stability and the influence of relevant parameters on the game player's strategy choices are analyzed. It aims to solve the following three problems. Firstly, how do the strategy choices of new media affect the behavior of government department, pharmaceutical enterprises and citizens in emergency management? Secondly, how does citizen participation affect the strategy choices of government department, pharmaceutical enterprises and new media? Thirdly, what is the influence of pharmaceutical enterprises' strategy choices on the strategy choices of government department, citizens and new media?

The rest of our paper is organized as follows. In section 2, we review relevant literature on public health events emergency management. And we make hypotheses and construct the game model in section 3. Section 4 contains the evolutionary stability analysis of each player's strategy choices. Then Section 5 is the stability analysis of the equilibrium points for the whole replicator dynamic system. In section 6, we use Matlab $2020 b$ to conduct numerical simulations, and analyze the influence of parameters on the strategy choices of each game player. Finally, the discussion is in section 7 and the conclusions are in section 8 .

\section{Literature Review}

In today's increasingly interconnected world, outbreak of infectious diseases can spread widely and cause considerable impact on public health (Lu X., et al, 2019). To 
cope with public health events, scholars have carried out extensive studies on the participation of the government department, pharmaceutical enterprises, citizens and new media in emergency management.

Facing the public health events, to protect the citizen health and ensure the normal operation of the economy, the government needs to weigh controlling the spread of the virus against the economic cost of adopting strict containment measures (Comfort L.K., et al, 2020). Following the COVID-19 outbreak in late 2019, governments around the world attempted to contain the pandemic by implementing the large-scale non-pharmaceutical interventions (NPI) at the individual level of citizens (Wu J.T., et al, 2020; Brauner J.M., et al, 2021). Among them, the Chinese government implemented rapid and comprehensive public health emergency intervention measures, including the ban on travel to and from Wuhan, the suspension of urban public transport and so on (Chinazzi M., et al, 2020; Tian H.Y., et al, 2020). In addition, Italy, the United States and many European countries also adopted non-pharmaceutical intervention measures, such as closing schools and city lockdowns, which has significantly delayed the growth of the epidemic and reduced the spread of the epidemic (Flaxman S., et al, 2020; Hsiang S., et al, 2020; Kraemer Moritz U.G., et al, 2020). Unlike those countries, the South Korean government didn't impose strict and enforced blockades on virus centers, but adopted transparent risk communication policies and mobilized public participation to contain the spread of the epidemic (Moon M.J., 2020).

In modern society, immunization is an indispensable mechanism for preventing infectious diseases caused by virus (Yong B.B., et al, 2020). Because of the novelty of virus, non-pharmaceutical interventions alone are not enough, so the rapid development and production of an effective vaccine is imperative to mitigate the effects of the epidemic on public health (Gao Q., et al, 2020; Krammer F., 2020). This requires the active participation of pharmaceutical enterprises. In emergency management, pharmaceutical enterprises can balance their economic goals and social goals by actively assuming social responsibility and positive citizen evaluation on such behavior of enterprises can improve their reputation and bring more potential customers (Rodell J.B., et al, 2020; Maon F., et al, 2021). Citizen participation in emergency management can enable public services to be effectively provided. The factors that affect the degree of citizen participation include the citizen's personal psychological orientation and personal service needs (Uzochukwu K., et al, 2018). 
The citizens can participate in emergency management by sharing relevant information. Their sense of self-worth, social support and reputation enhancement have a positive impact on information sharing. Therefore, in order to give full play to the role of citizens in emergency management supervision, the government should design a reasonable incentive mechanism to enhance the self-worth sense of citizens and social responsibility (Yan Z.J., et al, 2016; Sjoberg F.M., et al, 2017).

The development of modern information and communication technology has provided new possibilities for citizen participation in emergency management (Zhang F.X., et al, 2019). The use of social media impacts information accessibility, adaptability, proactiveness and resilience (Kavota J.K., et al, 2020). In emergency management of public health events, the use of social media by the citizens is booming, but whether this behavior has a positive or negative impact on emergency management has not been determined (Elbanna A., et al, 2019). Corporate reputation is an intangible asset for an enterprise, and the increase or decrease of reputation will bring value or loss (Wei J.C., et al, 2017). The rise of social media is changing the way corporate reputation is generated and spread in the public domain. Different ways of citizen evaluation and the enhancement of heterogeneity of media reputation will affect the formation of corporate reputation (Etter M., et al, 2019). New media can influence the reputation of enterprises through its ability to spread public opinion, bringing reputation value or reputation loss to enterprises, and thus affect the behavior and decision-making of enterprises (Blevins D.P., et al, 2019; Syed R., et al, 2019). The citizens can also participate in policy decision-making through social media. Government department should closely monitor the information on social media, attach importance to citizen participation and provide high-quality feedback (Lee J., et al, 2018; Liao Q.Y., et al, 2020).

To sum up, the existing literature mainly discusses the role of the government department, pharmaceutical enterprises, citizens and new media in the emergency management supervision from the perspective of a single party. There is still a lack of research that takes the government department, pharmaceutical enterprises, citizens and new media into account at the same time. In addition, the impact of the citizen evaluation's authenticity on other participants was not taken into account.

Therefore, the innovations of this paper are as follows. First of all, based on the emergency management of public health events, we consider the government department, pharmaceutical enterprises, citizens and new media as four players and 
construct a four-party game model. Secondly, considering the influence of citizens' true evaluation and false evaluation on the strategy choices of other participants, the evolutionary stable strategy combinations under different conditions are solved. Finally, we conduct the simulation analysis with Matlab 2020b to verify the influence of parameters on each game player's strategy choices and put forward suggestions for emergency management and supervision of public health events.

\section{Model Hypothesis and Construction}

Under the background of new media, we consider citizen participation, and the logical relationship of the government department, pharmaceutical enterprises, citizens and new media is shown in Figure 1.

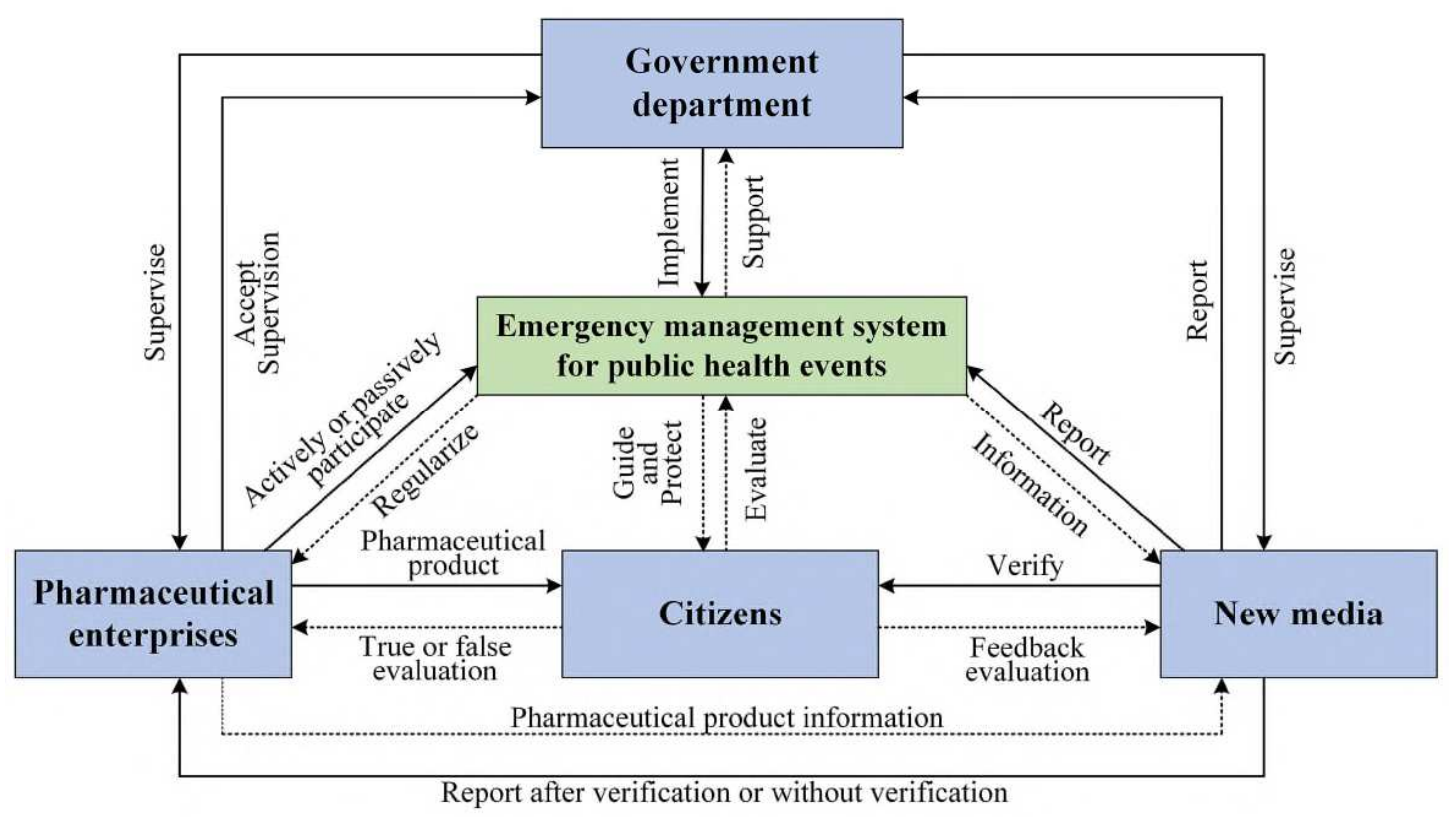

(Figure 1 The logical relationship of the four-party game model)

\subsection{Model Hypothesis}

Based on emergency management of public health events, we construct a game model involving the government department, pharmaceutical enterprises, citizens and new media. Then make the following hypotheses.

H1 Select the government department, pharmaceutical enterprises, citizens, and new media as the players of the game and the four players are bounded rational. The strategy choice space of government department is $S_{g}=\{$ Implement strictly, Not implement strictly $\}$, i.e., $S_{g}=\{$ IS, NIS $\}$. The strategy choice space of pharmaceutical enterprises is $S_{e}=\{$ Participate actively, Participate passively $\}$, i.e., $S_{e}=\{\mathrm{PA}, \mathrm{PP}\}$. The strategy choice space of citizens is $S_{p}=\{$ Evaluate truly, Evaluate falsely $\}$, i.e., $S_{p}$ 
$=\{\mathrm{ET}, \mathrm{EF}\}$. The strategy choice space of new media is $S_{m}=\{$ Report after verification, Report without verification $\}$, i.e., $S_{m}=\{$ RAV, RWV $\}$.

H2 The government department chooses "IS" with the probability of $g$, and chooses "NIS" with the probability of $(1-g)$. The pharmaceutical enterprises choose "PA" with the probability of $e$, and choose "PP" with the probability of $(1-e)$. The citizens choose "ET" with the probability of $p$, and choose "EF" with the probability of $(1-p)$. The new media choose "RAV" with the probability of $m$, and choose "RWV" with the probability of $(1-m)$. And $g, e, p, m \in[0,1]$.

H3 When the government department doesn't strictly implement the emergency management system, it only pays the daily administrative cost $C_{g}$. When it strictly implements, it needs to pay additional supervision cost $\Delta C_{g}$, and the subsidy it will obtain from the superior government is $M_{g}$. When pharmaceutical enterprises actively participate in emergency management, they can ensure the production capacity and quality, pay the cost $C_{e h}$, and obtain additional sales revenue $R_{e}$. When pharmaceutical enterprises passively participate, they pay the cost $C_{e l}$, and $C_{e l}<C_{e h}$. To encourage pharmaceutical enterprises to actively participate, the government department gives them subsidy $M_{e}$.If the pharmaceutical enterprises don't actively participate, they will be punished by the government department, and the punishment is $F_{e}$.

H4 The citizens can make evaluation on the behavior of pharmaceutical enterprises in emergency management, including true evaluation and false evaluation, and feedback the evaluation to new media, so as to expand the transmission speed and scope of evaluation. The new media will reward the citizens who provide true evaluation to encourage them to give true feedback, and the reward is set as $V_{p}$. The information value brought by the true evaluation of citizen feedback to new media is $V_{m}$. In addition, the cost of citizens making true evaluation is $C_{p t}$, and the cost of false evaluation is $C_{p f}$.

H5 As for the evaluation that citizens feedback, in order to ensure the authenticity of the report, new media may choose to report after verification, and the cost is $C_{m h}$. Or choose not to verify the report, in this case, the authenticity of the report can't be guaranteed, and the cost is $C_{m l}, C_{m l}<C_{m h}$. If new media choose report 
without verification, false evaluation will cause reputation loss $D_{e}$ to the pharmaceutical enterprises. At this time, the pharmaceutical enterprises will sue the new media, and the punishment for new media is $F_{m}$. Besides, due to the new media's false report, the public credibility of new media will decline, and the citizens will pay less attention to new media. The new media will lose pageview value $T_{m}$.

H6 When pharmaceutical enterprises don't actively participate in emergency management, the true evaluation will damage their reputation and cause loss $L_{e}$ to them. At this time, if the government department doesn't strictly implement the emergency management system, it will be punished by the superior government, and the punishment is $F_{g}$. When citizens make the false evaluation, if the new media verify it, they will expose the false evaluation, and they can obtain pageview revenue $R_{m}$. Then, the personal credit of citizens will be negatively affected, which will cause the loss of utility $U_{p}$, and they will also face punishment $F_{p}$.

Relevant parameters and meanings are shown in Table 1.

Table 1 Parameters and Meanings

\begin{tabular}{|c|c|c|c|}
\hline Parameter & Meaning & Parameter & Meaning \\
\hline$g$ & $\begin{array}{l}\text { The probability that the government department } \\
\text { chooses "Implement strictly". }\end{array}$ & $F_{e}$ & $\begin{array}{l}\text { The punishment when pharmaceutical } \\
\text { enterprises passively participate. }\end{array}$ \\
\hline$e$ & $\begin{array}{l}\text { The probability that pharmaceutical enterprises } \\
\text { choose "Participate actively". }\end{array}$ & $L_{e}$ & $\begin{array}{l}\text { The loss when pharmaceutical enterprises } \\
\text { passively participate. }\end{array}$ \\
\hline$p$ & $\begin{array}{l}\text { The probability that citizens choose "Evaluate } \\
\text { truly". }\end{array}$ & $C_{p t}$ & The cost of citizens making true evaluation. \\
\hline$m$ & $\begin{array}{l}\text { The probability that new media choose "Report } \\
\text { after verification". }\end{array}$ & $C_{p f}$ & The cost of citizens making false evaluation. \\
\hline$C_{g}$ & $\begin{array}{l}\text { The daily administrative cost of government } \\
\text { department not strictly implementing. }\end{array}$ & $U_{p}$ & $\begin{array}{l}\text { The utility loss of citizens when new media } \\
\text { expose the false evaluation. }\end{array}$ \\
\hline$\Delta C_{g}$ & $\begin{array}{l}\text { The additional supervision cost of government } \\
\text { department strictly implementing. }\end{array}$ & $F_{p}$ & $\begin{array}{l}\text { The punishment to citizens when they make } \\
\text { false evaluation. }\end{array}$ \\
\hline$M_{g}$ & $\begin{array}{l}\text { The subsidy that government department can } \\
\text { obtain when strictly implementing. }\end{array}$ & $V_{p}$ & $\begin{array}{l}\text { The reward from new media when citizens } \\
\text { make true evaluation. }\end{array}$ \\
\hline$F_{g}$ & $\begin{array}{l}\text { The punishment that government department } \\
\text { should bear when not strictly implementing. }\end{array}$ & $C_{m h}$ & $\begin{array}{l}\text { The cost that new media report after } \\
\text { verification. }\end{array}$ \\
\hline$C_{e h}$ & $\begin{array}{l}\text { The cost of pharmaceutical enterprises actively } \\
\text { participating. }\end{array}$ & $C_{m l}$ & $\begin{array}{l}\text { The cost that new media report without } \\
\text { verification. }\end{array}$ \\
\hline$C_{e l}$ & $\begin{array}{l}\text { The cost of pharmaceutical enterprises passively } \\
\text { participating. }\end{array}$ & $V_{m}$ & $\begin{array}{l}\text { The information value that new media can } \\
\text { obtain when citizens make true evaluation. }\end{array}$ \\
\hline$M_{e}$ & $\begin{array}{l}\text { The subsidy given by the government department } \\
\text { to pharmaceutical enterprises }\end{array}$ & $R_{m}$ & $\begin{array}{l}\text { The pageview revenue that new media can } \\
\text { obtain when they verify the false evaluation. }\end{array}$ \\
\hline$D_{e}$ & $\begin{array}{l}\text { The reputation loss when pharmaceutical } \\
\text { enterprises actively participate. }\end{array}$ & $T_{m}$ & $\begin{array}{l}\text { The new media's loss of pageview value } \\
\text { when they report false evaluation. }\end{array}$ \\
\hline$R_{e}$ & $\begin{array}{l}\text { The additional sales revenue when } \\
\text { pharmaceutical enterprises actively participate. }\end{array}$ & $F_{m}$ & $\begin{array}{l}\text { The punishment that new media should bear } \\
\text { when they report false evaluation. }\end{array}$ \\
\hline
\end{tabular}




\subsection{Model Construction}

Based on the above hypotheses, we construct a game matrix of the government department, pharmaceutical enterprises, citizens and new media in emergency management supervision, as shown in Table 2.

Table 2 The game matrix of the four-party in emergency management supervision

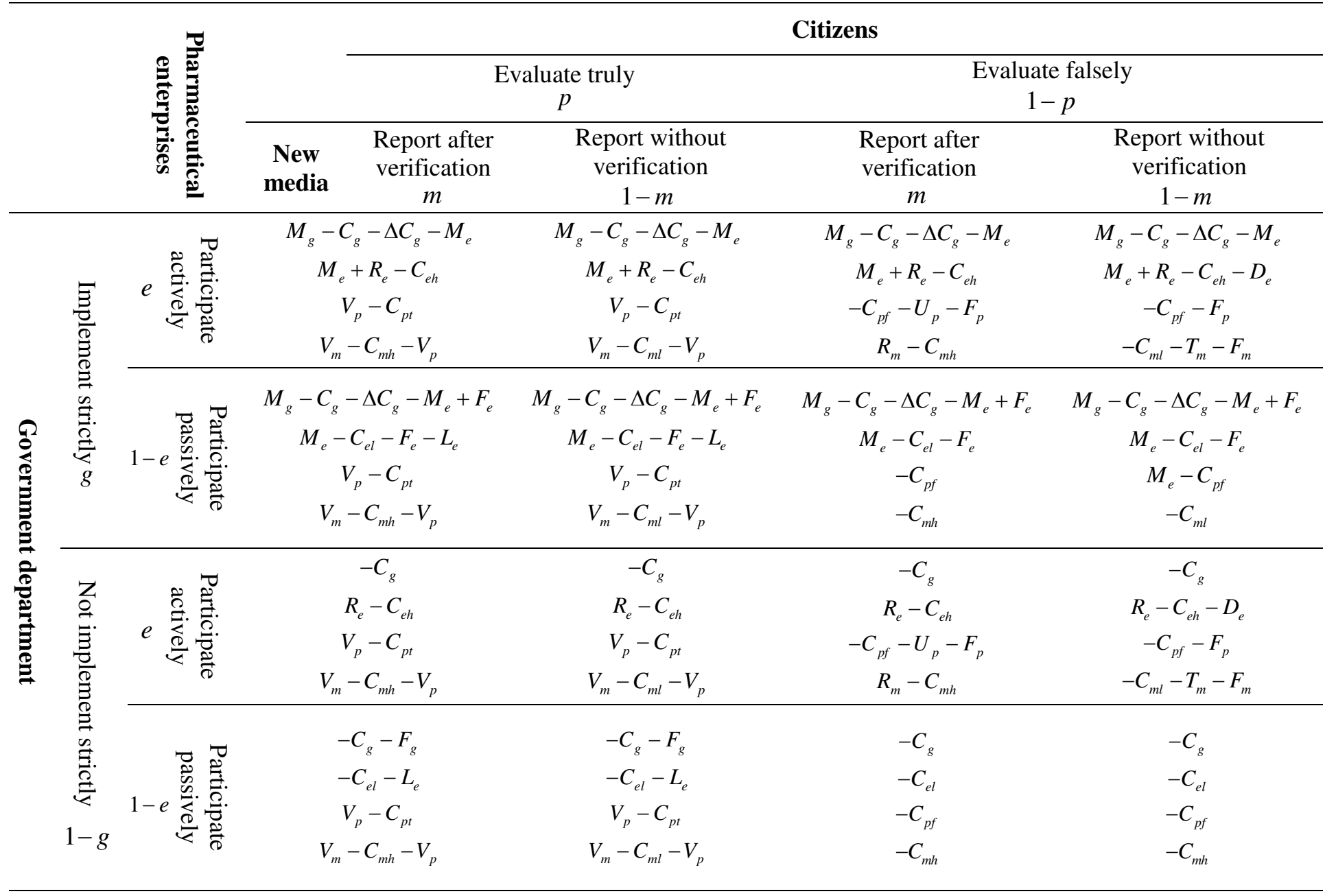

\section{Model Analysis}

\subsection{Evolutionary Stability Analysis of Government department's strategy}

The government department's expected return of choosing "Implement strictly" is

$$
\begin{aligned}
& E_{g}=\operatorname{epm}\left(M_{g}-C_{g}-\Delta C_{g}-M_{e}\right)+e p(1-m)\left(M_{g}-C_{g}-\Delta C_{g}-M_{e}\right)+e(1-p) m\left(M_{g}-C_{g}-\Delta C_{g}-M_{e}\right) \\
& +e(1-p)(1-m)\left(M_{g}-C_{g}-\Delta C_{g}-M_{e}\right)+(1-e) p m\left(M_{g}-C_{g}-\Delta C_{g}-M_{e}+F_{e}\right)+(1-e) p(1-m)\left(M_{g}-C_{g}-\Delta C_{g}-M_{e}+F_{e}\right) \\
& +(1-e)(1-p) m\left(M_{g}-C_{g}-\Delta C_{g}-M_{e}+F_{e}\right)+(1-e)(1-p)(1-m)\left(M_{g}-C_{g}-\Delta C_{g}-M_{e}+F_{e}\right) \\
& =M_{g}-C_{g}-\Delta C_{g}-M_{e}+(1-e) F_{e}
\end{aligned}
$$

The government department's expected return of choosing "Not implement strictly" 
is

$$
\begin{aligned}
& E_{1-g}=e p m\left(-C_{g}\right)+e p(1-m)\left(-C_{g}\right)+e(1-p) m\left(-C_{g}\right)+e(1-p)(1-m)\left(-C_{g}\right)+(1-e) p m\left(-C_{g}-F_{g}\right) \\
& +(1-e) p(1-m)\left(-C_{g}-F_{g}\right)+(1-e)(1-p) m\left(-C_{g}\right)+(1-e)(1-p)(1-m)\left(-C_{g}\right) \\
& =-C_{g}-(1-e) p F_{g}
\end{aligned}
$$

The replicator dynamic equation and its first derivative are

$$
\begin{aligned}
& F(g)=d g / d t=x\left(E_{g}-\bar{E}\right)=g(1-g)\left(E_{g}-E_{1-g}\right)=g(1-g)\left[M_{g}-\Delta C_{g}-M_{e}+(1-e) F_{e}+(1-e) p F_{g}\right] \\
& F^{\prime}(g)=(1-2 g)\left[M_{g}-\Delta C_{g}-M_{e}+(1-e) F_{e}+(1-e) p F_{g}\right]
\end{aligned}
$$

According to the fundamental theorem of stability of differential equations, when $F(g)=0$ and $F^{\prime}(g)<0$, the probability of government department's strategy choice is in a stable state.

Proposition 1 When $e<e_{0}$ or $p>p_{0}$, the evolutionary stable strategy of government department is "Implement strictly". When $e>e_{0}$ or $p<p_{0}$, the evolutionary stable strategy of government department is "Not implement strictly". When $e=e_{0}$ or $p=p_{0}$, there is no evolutionary stable strategy. The thresholds are $e_{0}=1-\left(M_{e}+\Delta C_{g}-M_{g}\right) /\left(F_{e}+p F_{g}\right)$ and $p_{0}=\left[M_{e}+\Delta C_{g}-M_{g}-(1-e) F_{e}\right] /\left[(1-e) F_{g}\right]$.

Proof Let $G(e, p)=M_{g}-\Delta C_{g}-M_{e}+(1-e) F_{e}+(1-e) p F_{g}$. When $G(e, p)=0$, we can get $e_{0}=1-\left(M_{e}+\Delta C_{g}-M_{g}\right) /\left(F_{e}+p F_{g}\right)$ and $p_{0}=\left[M_{e}+\Delta C_{g}-M_{g}-(1-e) F_{e}\right] /\left[(1-e) F_{g}\right]$. Take the first-order derivative of $G(e, p)$ with respect to $e$ and $p$, then get $\partial G(e, p) / \partial e<0$ and $\partial G(e, p) / \partial p>0$. So, $G(e, p)$ is a decreasing function of $e$, and an increasing function of $p$. When $e<e_{0}$ or $p>p_{0}$, there are $G(e, p)>0,\left.F^{\prime}(g)\right|_{g=1}<0$ and $\left.F(g)\right|_{g=1}=0$, then $g=1$ is the evolutionary stable strategy. When $e>e_{0}$ or $p<p_{0}$, there are $G(e, p)<0,\left.\quad F^{\prime}(g)\right|_{g=0}<0$ and $\left.F(g)\right|_{g=0}=0$, then $g=0$ is the evolutionary stable strategy. When $e=e_{0}$ or $p=p_{0}$, there are $G(e, p)=0$ and $F^{\prime}(g)=0$, so there doesn't exist evolutionary stable strategy.

To sum up, the response function of the probability of government department choosing "Implement strictly" is

$$
g=\left\{\begin{array}{ccccc}
0 & \text { if } & e>e_{0} & \text { or } & p<p_{0} \\
{[0,1]} & \text { if } & e=e_{0} & \text { or } & p=p_{0} \\
1 & \text { if } & e<e_{0} & \text { or } & p>p_{0}
\end{array}\right.
$$

The proposition 1 shows that in public health events, when the probability of 
pharmaceutical enterprises actively participating in emergency management is low or the probability of citizens making true evaluation is high, the probability of government department choosing "Implement strictly" will be stable at 1 . Therefore, when the enthusiasm of pharmaceutical enterprises to participate in the emergency management is insufficient, the government department will play a regulatory role; when the enthusiasm of pharmaceutical enterprises is high, the government department often have the phenomenon of dereliction of duty. In addition, the citizens' true evaluation on pharmaceutical enterprises will help promote the government department to exercise the regulatory role, that is, the citizens can play the supervisory role on both pharmaceutical enterprises and government department.

According to proposition 1, the evolutionary trend of government department's strategy is shown in Figure 2.
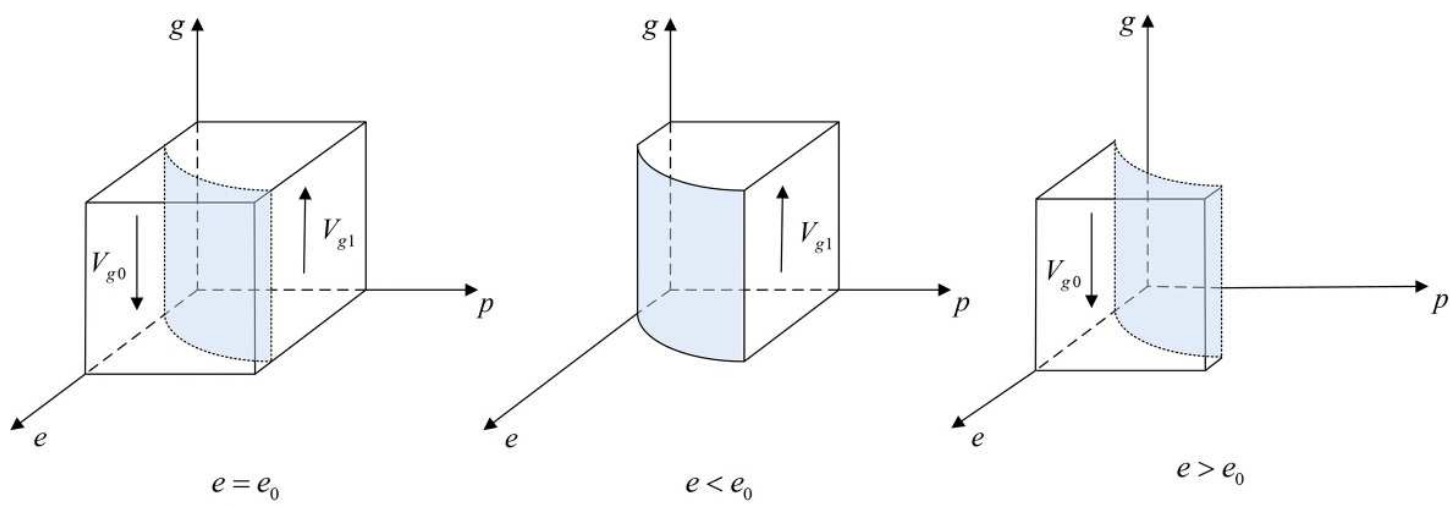

(Figure 2 The evolutionary trend of government department's strategy)

From Figure 2, the probability that government department chooses "Implement strictly" equals the volume $V_{g 1}$ and the probability that government department chooses "Not implement strictly" equals the volume $V_{g 0}$.

$$
\begin{aligned}
& V_{g 1}=\int_{0}^{1} \int_{0}^{1} 1-\frac{M_{e}+\Delta C_{g}-M_{g}}{F_{e}+p F_{g}} d p d g=1-\frac{M_{e}+\Delta C_{g}-M_{g}}{F_{g}} \ln \frac{F_{e}+F_{g}}{F_{e}} \\
& V_{g 0}=1-V_{g 1}=\frac{M_{e}+\Delta C_{g}-M_{g}}{F_{g}} \ln \frac{F_{e}+F_{g}}{F_{e}}
\end{aligned}
$$

Corollary 1.1 The probability that government department chooses "Not implement strictly" is positively correlated with additional supervision cost, and negatively correlated with the punishment imposed by the superior government.

Proof Take the first-order derivative of $V_{g 0}$ with respect to $\Delta C_{g}$ and $F_{g}$, and we can get 


$$
\begin{aligned}
& \frac{\partial V_{g 0}}{\partial \Delta C_{g}}=\frac{1}{F_{g}} \ln \frac{F_{e}+F_{g}}{F_{e}}>0 \\
& \frac{\partial V_{g 0}}{\partial F_{g}}=-\left[\frac{M_{e}+\Delta C_{g}-M_{g}}{F_{g}{ }^{2}} \ln \frac{F_{e}+F_{g}}{F_{e}}+\frac{M_{g}-\Delta C_{g}-M_{e}}{F_{g}\left(F_{e}+F_{g}\right)}\right]<0
\end{aligned}
$$

Corollary 1.1 indicates that the greater the additional supervision cost, the greater the probability that the government department will choose "Not implement strictly". And when the government department bears more punishment for not strictly implementing the emergency management system, the less likely it is to choose "Not implement strictly".

Corollary 1.2 The probability that government department chooses "Implement strictly" is positively correlated with the subsidy from the superior government and the punishment to pharmaceutical enterprises, and negatively correlated with the subsidy to pharmaceutical enterprises.

Proof Take the first-order derivative of $V_{g 1}$ with respect to $M_{g}, F_{e}$ and $M_{e}$, and we can get

$$
\begin{aligned}
& \frac{\partial V_{g 1}}{\partial M_{g}}=\frac{1}{F_{g}} \ln \frac{F_{e}+F_{g}}{F_{e}}>0 \\
& \frac{\partial V_{g 1}}{\partial F_{e}}=\frac{M_{e}+\Delta C_{g}-M_{g}}{F_{g}\left(F_{e}+F_{g}\right)}>0 \\
& \frac{\partial V_{g 1}}{\partial M_{e}}=-\frac{1}{F_{g}} \ln \frac{F_{e}+F_{g}}{F_{e}}<0
\end{aligned}
$$

Corollary 1.2 indicates that subsidy from the superior government can promote the government department to strictly implement the emergency management system, but the subsidy to pharmaceutical enterprises will reduce the enthusiasm of the government department to strictly implement. Besides, the greater the punishment imposed by government department on pharmaceutical enterprises, the greater the probability that government department will choose "Implement strictly".

Corollary 1.3 When the government department doesn't strictly implement the emergency management system, if the punishment imposed by the superior government satisfies $F_{g}>F_{g 0}$, the government department will choose "Implement strictly". But if $F_{g}<F_{g 0}$, the government department will choose "Not implement strictly". The threshold is $F_{g 0}=\left[M_{e}+\Delta C_{g}-M_{g}-(1-e) F_{e}\right] /(1-e) p$.

Proof According to proposition 1, when $G(e, p)=0$, we can get 
$F_{g 0}=\left[M_{e}+\Delta C_{g}-M_{g}-(1-e) F_{e}\right] /(1-e) p$. Take the first-order derivative of $G(e, p)$ with respect to $F_{g}$, and get $\partial G(e, p) / \partial F_{g}>0$. So, $G(e, p)$ is an increasing function of $F_{g}$. When $F_{g}>F_{g 0}$, there are $G(e, p)>0$ and $\left.F^{\prime}(g)\right|_{g=1}<0$. When $F_{g}<F_{g 0}$, there are $G(e, p)<0$ and $\left.F^{\prime}(g)\right|_{g=0}<0$.

Corollary 1.3 indicates that when the punishment $F_{g}$ imposed by the superior government is greater than the threshold $F_{g 0}$, the government department will choose "Implement strictly". When $F_{g}$ is less than the threshold $F_{g 0}$, the government department will choose "Not implement strictly". Therefore, the superior government should formulate a severe punishment mechanism to urge the government department to strictly implement the emergency management system.

\subsection{Evolutionary Stability Analysis of pharmaceutical enterprises' strategy}

The pharmaceutical enterprises' expected return of choosing "Participate actively" is

$$
\begin{aligned}
& E_{e}=g p m\left(M_{e}-C_{e h}+R_{e}\right)+g p(1-m)\left(M_{e}-C_{e h}+R_{e}\right)+g(1-p) m\left(M_{e}-C_{e h}+R_{e}\right)+g(1-p)(1-m)\left(M_{e}-C_{e h}+R_{e}-D_{e}\right) \\
& +(1-g) \operatorname{pm}\left(R_{e}-C_{e h}\right)+(1-g) p(1-m)\left(R_{e}-C_{e h}\right)+(1-g)(1-p) m\left(R_{e}-C_{e h}\right)+(1-g)(1-p)(1-m)\left(R_{e}-C_{e h}-D_{e}\right) \\
& =R_{e}+g M_{e}-C_{e h}-(1-p)(1-m) D_{e}
\end{aligned}
$$

The pharmaceutical enterprises' expected return of choosing "Participate passively" is

$$
\begin{aligned}
& E_{1-e}=g p m\left(M_{e}-C_{e l}-F_{e}-L_{e}\right)+g p(1-m)\left(M_{e}-C_{e l}-F_{e}-L_{e}\right)+g(1-p) m\left(M_{e}-C_{e l}-F_{e}\right)+g(1-p)(1-m)\left(M_{e}-C_{e l}-F_{e}\right) \\
& +(1-g) p m\left(-C_{e l}-L_{e}\right)+(1-g) p(1-m)\left(-C_{e l}-L_{e}\right)+(1-g)(1-p) m\left(-C_{e l}\right)+(1-g)(1-p)(1-m)\left(-C_{e l}\right) \\
& =g M_{e}-C_{e l}-g F_{e}-p L_{e}
\end{aligned}
$$

The replicator dynamic equation and its first derivative are

$$
\begin{aligned}
& F(e)=d e / d t=e\left(E_{e}-\bar{E}\right)=e(1-e)\left(E_{e}-E_{1-e}\right)=e(1-e)\left[R_{e}+C_{e l}-C_{e h}-(1-p)(1-m) D_{e}+g F_{e}+p L_{e}\right] \\
& F^{\prime}(e)=(1-2 e)\left[R_{e}+C_{e l}-C_{e h}-(1-p)(1-m) D_{e}+g F_{e}+p L_{e}\right]
\end{aligned}
$$

According to the fundamental theorem of stability of differential equations, when $F(e)=0$ and $F^{\prime}(e)<0$, the probability of pharmaceutical enterprises' strategy choice is in a stable state.

Proposition 2 When $g>g_{1}, \quad p>p_{1}$ or $m>m_{1}$, the evolutionary stable strategy of pharmaceutical enterprises is "Participate actively". When $g<g_{1}, \quad p<p_{1}$ or $m<m_{1}$, the evolutionary stable strategy of pharmaceutical enterprises is "Participate 
passively". When $g=g_{1}, \quad p=p_{1}$ or $m=m_{1}$, there is no evolutionary stable strategy. The thresholds are $g_{1}=\left[C_{e h}-C_{e l}-R_{e}+(1-p)(1-m) D_{e}-p L_{e}\right] / F_{e}, \quad p_{1}=\left[C_{e h}-C_{d}-R_{e}+(1-m) D_{e}-g F_{e}\right] /\left[L_{e}+(1-m) D_{e}\right]$ and $m_{1}=1-\left[R_{e}+C_{e l}-C_{e h}+g F_{e}+p L_{e}\right] /(1-p) D_{e}$.

Proof Let $H(g, p, m)=R_{e}+C_{e l}-C_{e h}-(1-p)(1-m) D_{e}+g F_{e}+p L_{e}$. When $H(g, p, m)=0$, we can get $g_{1}=\left[C_{e h}-C_{e l}-R_{e}+(1-p)(1-m) D_{e}-p L_{e}\right] / F_{e}, \quad p_{1}=\left[C_{e h}-C_{e l}-R_{e}+(1-m) D_{e}-g F_{e}\right] /\left[L_{e}+(1-m) D_{e}\right]$ and $m_{1}=1-\left[R_{e}+C_{e l}-C_{e h}+g F_{e}+p L_{e}\right] /(1-p) D_{e}$. Take the first-order derivative of $H(g, p, m)$ with respect to $g, p$ and $m$, then get $\partial H(g, p, m) / \partial g>0, \partial H(g, p, m) / \partial p>0$ and $\partial H(g, p, m) / \partial m>0$. So, $H(g, p, m)$ is an increasing function of $g, p$ and $m$. When $g>g_{1}, \quad p>p_{1}$ or $m>m_{1}$, there are $H(g, p, m)>0,\left.\quad F^{\prime}(e)\right|_{e=1}<0$ and $\left.F(e)\right|_{e=1}=0$, then $e=1$ is the evolutionary stable strategy. When $g<g_{1}, \quad p<p_{1}$ or $m<m_{1}$, there are $H(g, p, m)<0,\left.F^{\prime}(e)\right|_{e=0}<0$ and $\left.F(e)\right|_{e=0}=0$, then $e=0$ is the evolutionary stable strategy. When $g=g_{1}, p=p_{1}$ or $m=m_{1}$, there are $H(g, p, m)=0$ and $F^{\prime}(e)=0$, so there doesn't exist evolutionary stable strategy.

To sum up, the response function of the probability of pharmaceutical enterprises choosing "Participate passively" is

$$
e=\left\{\begin{array}{ccccccc}
0 & \text { if } & g<g_{1} & \text { or } & p<p_{1} & \text { or } & m<m_{1} \\
{[0,1]} & \text { if } & g=g_{1} & \text { or } & p=p_{1} & \text { or } & m=m_{1} \\
1 & \text { if } & g>g_{1} & \text { or } & p>p_{1} & \text { or } & m>m_{1}
\end{array}\right.
$$

The proposition 2 shows that with the probability of government department choosing "Implement strictly", the citizens choosing "Evaluate truly" and the new media choosing "Report after verification" increasing, the stability strategy of pharmaceutical enterprises will change from "Participate passively" to "Participate actively". Thus, the government department strictly implementing the emergency management helps to promote pharmaceutical enterprises to actively participate. And the citizens' true evaluation and the new media's verification can also play a supervisory role to pharmaceutical enterprises.

According to proposition 2, the evolutionary trend of pharmaceutical enterprises' strategy is shown in Figure 3. 

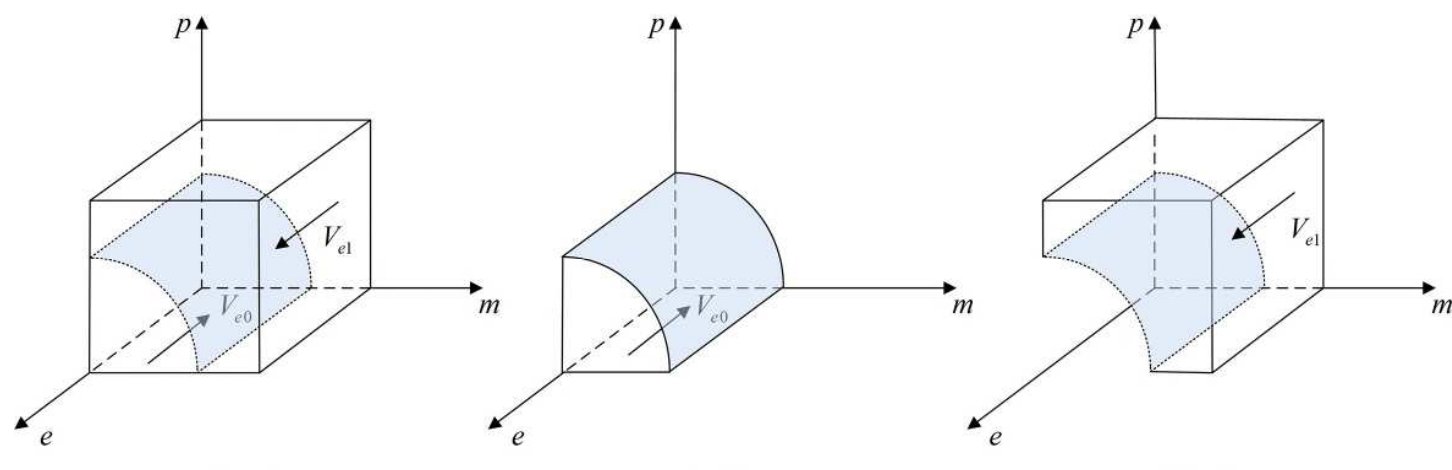

$$
p=p_{1}
$$

$p<p_{1}$

$p>p_{1}$

(Figure 3 The evolutionary trend of pharmaceutical enterprises' strategy)

From Figure 3, the probability that pharmaceutical enterprises choose "Participate actively" equals the volume $V_{e 1}$ and the probability that pharmaceutical enterprises choose "Participate passively" equals the volume $V_{e 0}$.

$$
\begin{aligned}
& V_{e 0}=\int_{0}^{1} \int_{0}^{1-\frac{R_{e}+C_{e l}-C_{e h}+g F_{e}}{D_{e}}} \frac{C_{e h}-C_{e l}-R_{e}+(1-m) D_{e}-g F_{e}}{L_{e}+(1-m) D_{e}} d m d e \\
& =1-\frac{R_{e}+C_{e l}-C_{e h}+g F_{e}}{D_{e}}+\frac{R_{e}+C_{e l}-C_{e h}+g F_{e}+L_{e}}{D_{e}} \ln \frac{R_{e}+C_{e l}-C_{e h}+g F_{e}+L_{e}}{D_{e}+L_{e}} \\
& V_{e 1}=1-V_{e 0}=\frac{R_{e}+C_{e l}-C_{e h}+g F_{e}}{D_{e}}-\frac{R_{e}+C_{e l}-C_{e h}+g F_{e}+L_{e}}{D_{e}} \ln \frac{R_{e}+C_{e l}-C_{e h}+g F_{e}+L_{e}}{D_{e}+L_{e}}
\end{aligned}
$$

Corollary 2.1 The probability of pharmaceutical enterprises choosing "Participate passively" is positively correlated with the extra cost when actively participating, and negatively correlated with the additional sales revenue.

Proof Take the first-order derivative of $V_{e 0}$ with respect to $\left(C_{e h}-C_{e l}\right)$ and $R_{e}$, and we can get

$$
\begin{aligned}
& \frac{\partial V_{e 0}}{\partial\left(C_{e h}-C_{e l}\right)}=\frac{1}{D_{e}} \ln \frac{D_{e}+L_{e}}{R_{e}+C_{e l}-C_{e h}+g F_{e}+L_{e}}>0 \\
& \frac{\partial V_{e 0}}{\partial R_{e}}=-\frac{1}{D_{e}} \ln \frac{D_{e}+L_{e}}{R_{e}+C_{e l}-C_{e h}+g F_{e}+L_{e}}<0
\end{aligned}
$$

Corollary 1.2 indicates that the greater the extra cost that pharmaceutical enterprises pay when actively participating in emergency management, the greater the probability that they choose "Participate passively". As pharmaceutical enterprises participate actively, the more additional sales revenue they gain, the less likely they are to choose "Participate passively".

Corollary 2.2 The greater the probability that government department chooses "Implement strictly" and the greater the punishment that pharmaceutical enterprises should bear when they don't actively participate, the greater the probability that 
pharmaceutical enterprises actively participate in emergency management.

Proof Take the first-order derivative of $V_{e 1}$ with respect to $g$ and $F_{e}$, and we can get

$$
\begin{aligned}
& \frac{\partial V_{e 1}}{\partial g}=\frac{F_{e}}{D_{e}} \ln \frac{D_{e}+L_{e}}{R_{e}+C_{e l}-C_{e h}+g F_{e}+L_{e}}>0 \\
& \frac{\partial V_{e 1}}{\partial F_{e}}=\frac{g}{D_{e}} \ln \frac{D_{e}+L_{e}}{R_{e}+C_{e l}-C_{e h}+g F_{e}+L_{e}}>0
\end{aligned}
$$

Corollary 2.2 indicates that government department strictly implementing the emergency management system can improve the probability that pharmaceutical enterprises actively participate in emergency management. When pharmaceutical enterprises don't participate actively, the greater the punishment imposed by government department on them, the greater the probability that pharmaceutical enterprises will choose "Participate actively".

Corollary 2.3 When pharmaceutical enterprises don't participate actively, if the loss caused by the citizen true evaluation satisfies $L_{e}>L_{e 1}$, pharmaceutical enterprises will choose "Participate actively". But if $L_{e}<L_{e 1}$, pharmaceutical enterprises will choose "Participate passively". The threshold is $L_{e 1}=\left[C_{e h}-C_{e l}-R_{e}+(1-p)(1-m) D_{e}-g F_{e}\right] / p$.

Proof According to proposition 2, when $H(g, p, m)=0$, we can get $L_{e 1}=\left[C_{e h}-C_{e l}-R_{e}+(1-p)(1-m) D_{e}-g F_{e}\right] / p$. Take the first-order derivative of $H(g, p, m)$ with respect to $L_{e}$, and get $\partial H(g, p, m) / \partial L_{e}>0$. So, $H(g, p, m)$ is an increasing function of $L_{e}$. When $L_{e}>L_{e 1}$, there are $H(g, p, m)>0$ and $\left.F^{\prime}(e)\right|_{e=1}<0$. When $L_{e}<L_{e 1}$, there are $H(g, p, m)<0$ and $\left.F^{\prime}(e)\right|_{e=0}<0$.

Corollary 2.3 indicates that when the loss $L_{e}$ is greater than the threshold $L_{e 1}$, the pharmaceutical enterprises will choose "Participate actively". When $L_{e}$ is less than the threshold $L_{e 1}$, the pharmaceutical enterprises will choose "Participate passively". Therefore, improving the impact of citizen evaluation on the loss of pharmaceutical enterprises can play a supervisory role of citizens. Government department should open the channels of citizen evaluation, so as to expand the impact of citizen evaluation on pharmaceutical enterprises.

Corollary 2.4 When pharmaceutical enterprises participate actively, if the reputation loss caused by citizen false evaluation satisfies $D_{e}<D_{e 1}$, pharmaceutical 
enterprises will choose "Participate actively". But if $D_{e}>D_{e 1}$, pharmaceutical enterprises will choose "Participate passively". The threshold is $D_{e 1}=\left(R_{e}+C_{e l}-C_{e h}+g F_{e}+p L_{e}\right) /(1-p)(1-m)$.

Proof According to proposition 2, when $H(g, p, m)=0$, we can get $D_{e 1}=\left(R_{e}+C_{e l}-C_{e h}+g F_{e}+p L_{e}\right) /(1-p)(1-m)$. Take the first-order derivative of $H(g, p, m)$ with respect to $D_{e}$, and get $\partial H(g, p, m) / \partial D_{e}<0$. So, $H(g, p, m)$ is a decreasing function of $D_{e}$. When $D_{e}<D_{e 1}$, there are $H(g, p, m)>0$ and $\left.F^{\prime}(e)\right|_{e=1}<0$. When $D_{e}>D_{e 0}$, there are $H(g, p, m)<0$ and $\left.F^{\prime}(e)\right|_{e=0}<0$.

Corollary 2.4 indicates that when the reputation loss $D_{e}$ caused by citizen false evaluation is less than the threshold $D_{e 1}$, the pharmaceutical enterprises will choose "Participate actively". When $D_{e}$ is greater than the threshold $D_{e 1}$, the pharmaceutical enterprises will choose "Participate passively". So, government department should increase the punishment for spreading rumor, strengthen the supervision to new media reports, and urge new media to verify the evaluation of citizen feedback, so as not to damage the enthusiasm of pharmaceutical enterprises to participate in emergency management.

\subsection{Evolutionary Stability Analysis of citizens' strategy}

The citizens' expected return of choosing "Evaluate truly" is

$$
\begin{aligned}
& E_{p}=g e m\left(V_{p}-C_{p t}\right)+g e(1-m)\left(V_{p}-C_{p t}\right)+g(1-e) m\left(V_{p}-C_{p t}\right)+g(1-e)(1-m)\left(V_{p}-C_{p t}\right) \\
& +(1-g) e m\left(V_{p}-C_{p t}\right)+(1-g) e(1-m)\left(V_{p}-C_{p t}\right)+(1-g)(1-e) m\left(V_{p}-C_{p t}\right)+(1-g)(1-e)(1-m)\left(V_{p}-C_{p t}\right) \\
& =V_{p}-C_{p t}
\end{aligned}
$$

The citizens' expected return of choosing "Evaluate falsely" is

$$
\begin{aligned}
& E_{1-p}=g e m\left(-C_{p f}-U_{p}-F_{p}\right)+g e(1-m)\left(-C_{p f}-F_{p}\right)+g(1-e) m\left(-C_{p f}\right)+g(1-e)(1-m)\left(-C_{p f}\right) \\
& +(1-g) e m\left(-C_{p f}-U_{p}-F_{p}\right)+(1-g) e(1-m)\left(-C_{p f}-F_{p}\right)+(1-g)(1-e) m\left(-C_{p f}\right)+(1-g)(1-e)(1-m)\left(-C_{p f}\right) \\
& =-C_{p f}-e m U_{p}-e F_{p}
\end{aligned}
$$

The replicator dynamic equation and its first derivative are

$$
\begin{aligned}
& F(p)=d p / d t=p\left(E_{p}-\bar{E}\right)=p(1-p)\left(E_{p}-E_{1-p}\right)=p(1-p)\left(V_{p}-C_{p t}+C_{p f}+e m U_{p}+e F_{p}\right) \\
& F^{\prime}(p)=(1-2 p)\left(V_{p}-C_{p t}+C_{p f}+e m U_{p}+e F_{p}\right)
\end{aligned}
$$

According to the fundamental theorem of stability of differential equations, when $F(p)=0$ and $F^{\prime}(p)<0$, the probability of citizens' strategy choice is in a stable state. 
Proposition 3 When $e>e_{2}$ or $m>m_{2}$, the evolutionary stable strategy of citizens is "Evaluate truly". When $e<e_{2}$ or $m<m_{2}$, the evolutionary stable strategy of citizens is "Evaluate falsely". When $e=e_{2}$ or $m=m_{2}$, there is no evolutionary stable strategy. The thresholds are $e_{2}=\left(C_{p t}-C_{p f}-V_{p}\right) /\left(F_{p}+m U_{p}\right)$ and $m_{2}=\left(C_{p t}-C_{p f}-V_{p}-e F_{p}\right) / e U_{p}$.

Proof Let $J(e, m)=V_{p}-C_{p t}+C_{p f}+e m U_{p}+e F_{p}$. When $J(e, m)=0$, we can get $e_{2}=\left(C_{p t}-C_{p f}-V_{p}\right) /\left(F_{p}+m U_{p}\right)$ and $m_{2}=\left(C_{p t}-C_{p f}-V_{p}-e F_{p}\right) / e U_{p}$. Take the first-order derivative of $J(e, m)$ with respect to $e$ and $m$, then get $\partial J(e, m) / \partial e>0$ and $\partial J(e, m) / \partial m>0$. So, $J(e, m)$ is an increasing function of $e$ and $m$. When $e>e_{2}$ or $m>m_{2}$, there are $J(e, m)>0,\left.F^{\prime}(p)\right|_{p=1}<0$ and $\left.F(p)\right|_{p=1}=0$, then $p=1$ is the evolutionary stable strategy. When $e<e_{2}$ or $m<m_{2}$, there are $J(e, m)<0$, $\left.F^{\prime}(p)\right|_{p=0}<0$ and $\left.F(p)\right|_{p=0}=0$, then $p=0$ is the evolutionary stable strategy. When $e=e_{2}$ or $m=m_{2}$, there are $J(e, m)=0$ and $F^{\prime}(p)=0$, so there doesn't exist evolutionary stable strategy.

To sum up, the response function of the probability of citizens choosing "Evaluate truly" is

$$
p=\left\{\begin{array}{ccccc}
0 & \text { if } & e<e_{2} & \text { or } & m<m_{2} \\
{[0,1]} & \text { if } & e=e_{2} & \text { or } & m=m_{2} \\
1 & \text { if } & e>e_{2} & \text { or } & m>m_{2}
\end{array}\right.
$$

The proposition 3 shows that with the probability of pharmaceutical enterprises actively participating increasing, the citizens' stability strategy will change from "Evaluate falsely" to "Evaluate truly". When the probability of new media choosing the "Report after verification" strategy is high, the citizens' stable strategy is "Evaluate truly". In other words, when pharmaceutical enterprises actively participate in emergency management, the citizens are more inclined to make true evaluation, and the verification by new media can improve the probability of the citizens making true evaluation.

According to proposition 3, the evolutionary trend of citizens' strategy is shown in Figure 4. 

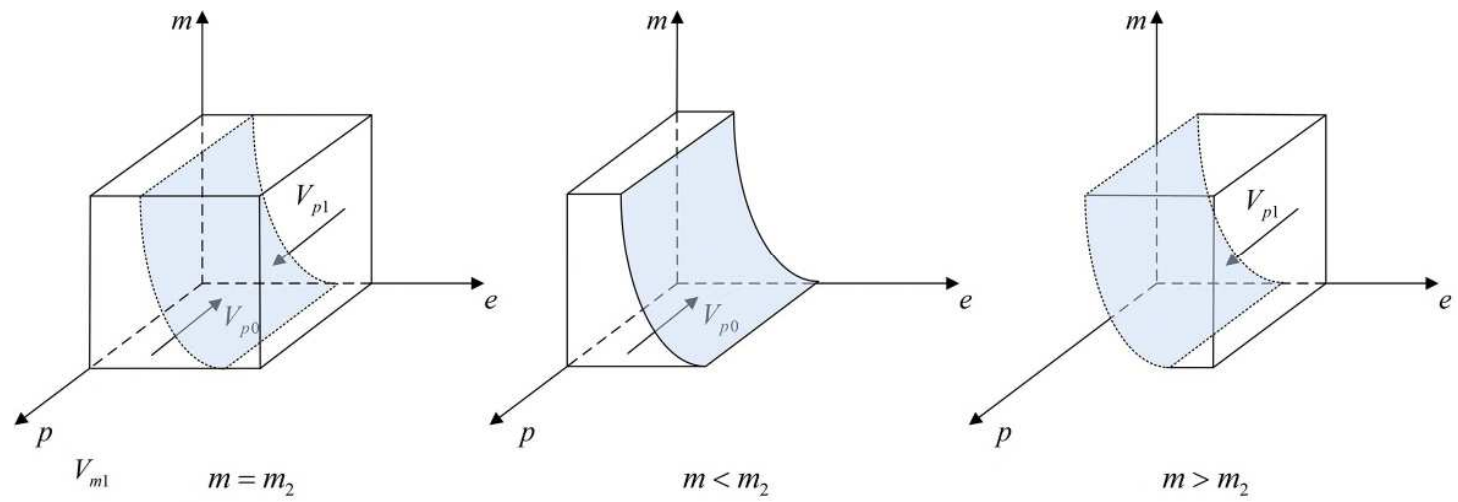

(Figure 4 The evolutionary trend of citizens' strategy)

From Figure 4, the probability that citizens choose "Evaluate truly" equals the volume $V_{p 1}$ and the probability that citizens choose "Evaluate falsely" equals the volume $V_{p 0}$.

$$
\begin{aligned}
& V_{p 0}=\int_{0}^{1} \int_{\frac{C_{p r}}{C_{p t}-C_{p t}-V_{p}-V_{p}}}^{\frac{C_{p}}{F_{p}+U_{p}}} \frac{C_{p t}-C_{p f}-V_{p}-e F_{p}}{e U_{p}} \operatorname{dedp}=\frac{C_{p t}-C_{p f}-V_{p}}{U_{p}} \ln \frac{F_{p}+U_{p}}{F_{p}} \\
& V_{p 1}=1-V_{p 0}=1-\frac{C_{p t}-C_{p f}-V_{p}}{U_{p}} \ln \frac{F_{p}+U_{p}}{F_{p}}
\end{aligned}
$$

Corollary 3.1 The probability of citizens choosing "Evaluate falsely" is negatively correlated with the cost of false evaluation and the reward from new media, and positively correlated with the cost of true evaluation.

Proof Take the first-order derivative of $V_{p 0}$ with respect to $C_{p f}, V_{p}$ and $C_{p t}$, and we can get

$$
\begin{aligned}
& \frac{\partial V_{p 0}}{\partial C_{p f}}=-\frac{1}{U_{p}} \ln \frac{F_{p}+U_{p}}{U_{p}}<0 \\
& \frac{\partial V_{p 0}}{\partial V_{p}}=-\frac{1}{U_{p}} \ln \frac{F_{p}+U_{p}}{U_{p}}<0 \\
& \frac{\partial V_{p 0}}{\partial C_{p t}}=\frac{1}{U_{p}} \ln \frac{F_{p}+U_{p}}{U_{p}}>0
\end{aligned}
$$

Corollary 3.1 indicates that as the cost of false evaluation decreases or the cost of true evaluation increases, the probability of the citizens choosing "Evaluate falsely" increases. The probability of "Evaluate truly" will decrease when the citizens obtain less reward for making true evaluation.

Corollary 3.2 The probability of citizens choosing "Evaluate truly" is positively correlated with the loss of utility and punishment caused by the false evaluation.

Proof Take the first-order derivative of $V_{p 1}$ with respect to $U_{p}$ and $F_{p}$, and we 
can get

$$
\begin{aligned}
& \frac{\partial V_{p 1}}{\partial U_{p}}=\frac{C_{p t}-C_{p f}-V_{p}}{U_{p}}\left(U_{p} \ln \frac{F_{p}+U_{p}}{F_{p}}-\frac{1}{F_{p}+U_{p}}\right)>0 \\
& \frac{\partial V_{p 1}}{\partial F_{p}}=\frac{C_{p t}-C_{p f}-V_{p}}{F_{p}\left(F_{p}+U_{p}\right)}>0
\end{aligned}
$$

Corollary 3.2 indicates that when the citizens make false evaluation, the greater the loss of utility, the greater the probability that citizens choose "Evaluate truly". In addition, the greater the punishment that citizens should bear due to false evaluation, the smaller the probability of citizens choosing "Evaluate falsely".

Corollary 3.3 When the citizens make false evaluation, if the punishment that citizens should bear satisfies $F_{p}>F_{p 2}$, the citizens will choose "Evaluate truly". But if $F_{p}<F_{p 2}$, the citizens will choose "Evaluate falsely". The threshold is $F_{p 2}=\left(C_{p t}-C_{p f}-V_{p}-e m U_{p}\right) / e$.

Proof According to proposition 3, when $J(e, m)=0$, we can get $F_{p 2}=\left(C_{p t}-C_{p f}-V_{p}-e m U_{p}\right) / e$. Take the first-order derivative of $J(e, m)$ with respect to $F_{p}$, and get $\partial J(e, m) / \partial F_{p}>0$. So, $J(e, m)$ is an increasing function of $F_{p}$. When $F_{p}>F_{p 2}$, there are $J(e, m)>0$ and $\left.F^{\prime}(p)\right|_{p=1}<0$. When $F_{p}<F_{p 2}$, there are $J(e, m)<0$ and $\left.F^{\prime}(p)\right|_{p=0}<0$.

Corollary 3.3 indicates that when the punishment $F_{p}$ that citizens should bear due to the false evaluation is greater than the threshold $F_{p 2}$, the citizens will choose "Evaluate truly". When $F_{p}$ is less than he threshold $F_{p 2}$, the citizens will choose "Evaluate falsely". Therefore, in order to improve the probability of citizens true evaluation and give play to the citizens' supervisory role, the government department should increase the punishment to the rumor-monger and rumor-spreading to increase the cost of false evaluation.

\subsection{Evolutionary Stability Analysis of new media's strategy}

The new media's expected return of choosing "Report after verification" is

$$
\begin{aligned}
& E_{m}=g e p\left(V_{m}-C_{m h}-V_{p}\right)+g(1-e) p\left(V_{m}-C_{m h}-V_{p}\right)+(1-g) e p\left(V_{m}-C_{m h}-V_{p}\right)+(1-g)(1-e) p\left(V_{m}-C_{m h}-V_{p}\right) \\
& +g e(1-p)\left(R_{m}-C_{m h}\right)+g(1-e)(1-p)\left(-C_{m h}\right)+(1-g) e(1-p)\left(R_{m}-C_{m h}\right)+(1-g)(1-e)(1-p)\left(-C_{m h}\right) \\
& =-C_{m h}+p V_{m}-p V_{p}+e(1-p) R_{m}
\end{aligned}
$$

The new media's expected return of choosing "Report without verification" is 


$$
\begin{aligned}
& E_{1-m}=g e p\left(V_{m}-C_{m l}-V_{p}\right)+g(1-e) p\left(V_{m}-C_{m l}-V_{p}\right)+(1-g) e p\left(V_{m}-C_{m l}-V_{p}\right)+(1-g)(1-e) p\left(V_{m}-C_{m l}-V_{p}\right) \\
& +g e(1-p)\left(-C_{m l}-T_{m}-F_{m}\right)+g(1-e)(1-p)\left(-C_{m l}\right)+(1-g) e(1-p)\left(-C_{m l}-T_{m}-F_{m}\right)+(1-g)(1-e)(1-p)\left(-C_{m l}\right) \\
& =-C_{m l}+p V_{m}-p V_{p}-e(1-p)\left(T_{m}+F_{m}\right)
\end{aligned}
$$

The replicator dynamic equation and its first derivative are

$$
\begin{aligned}
& F(m)=d m / d t=m\left(E_{m}-\bar{E}\right)=m(1-m)\left[C_{m l}-C_{m h}+e(1-p)\left(R_{m}+T_{m}+F_{m}\right)\right] \\
& F^{\prime}(m)=(1-2 m)\left[C_{m l}-C_{m h}+e(1-p)\left(R_{m}+T_{m}+F_{m}\right)\right]
\end{aligned}
$$

According to the fundamental theorem of stability of differential equations, when $F(m)=0$ and $F^{\prime}(m)<0$, the probability of new media's strategy choice is in a stable state.

Proposition 4 When $e>e_{3}$ or $p<p_{3}$ the evolutionary stable strategy of new media is "Report after verification". When $e<e_{3}$ or $p>p_{3}$, the evolutionary stable strategy of new media is "Report without verification". When $e=e_{3}$ or $p=p_{3}$, there is no evolutionary stable strategy. The thresholds are $e_{3}=\left(C_{m h}-C_{m l}\right) /(1-p)\left(R_{m}+T_{m}+F_{m}\right)$ and $p_{3}=1-\left(C_{m h}-C_{m l}\right) / e\left(R_{m}+T_{m}+F_{m}\right)$.

Proof Let $K(e, p)=C_{m l}-C_{m h}+e(1-p)\left(R_{m}+T_{m}+F_{m}\right)$. When $K(e, p)=0$, we can get $e_{3}=\left(C_{m h}-C_{m l}\right) /(1-p)\left(R_{m}+T_{m}+F_{m}\right)$ and $p_{3}=1-\left(C_{m h}-C_{m l}\right) / e\left(R_{m}+T_{m}+F_{m}\right)$. Take the first-order derivative of $K(e, p)$ with respect to $e$ and $p$, then get $\partial K(e, p) / \partial e>0$ and $\partial K(e, p) / \partial p<0$. So, $K(e, p)$ is an increasing function of $e$, and a decreasing function of $p$. When $e>e_{3}$ or $p<p_{3}$, there are $K(e, p)>0,\left.F^{\prime}(m)\right|_{m=1}<0$ and $\left.F(m)\right|_{m=1}=0$, then $m=1$ is the evolutionary stable strategy. When $e<e_{3}$ or $p>p_{3}$, there are $K(e, p)<0,\left.\quad F^{\prime}(m)\right|_{m=0}<0$ and $\left.F(m)\right|_{m=0}=0$, then $m=0$ is the evolutionary stable strategy. When $e=e_{3}$ or $p=p_{3}$, there are $K(e, p)=0$ and $F^{\prime}(m)=0$, so there doesn't exist evolutionary stable strategy.

To sum up, the response function of the probability of new media choosing "Report after verification" is

$$
m=\left\{\begin{array}{cllll}
0 & \text { if } & e<e_{3} & \text { or } & p>p_{3} \\
{[0,1]} & \text { if } & e=e_{3} & \text { or } & p=p_{3} \\
1 & \text { if } & e>e_{3} & \text { or } & p<p_{3}
\end{array}\right.
$$

The proposition 4 shows that with the probability that pharmaceutical enterprises actively participate in emergency management increasing, the stability strategy of new media will change from "Report without verification" to "Report after verification". 
When the probability that citizens feedback true evaluation is low, the stability strategy of new media will also change from "Report without verification" to "Report after verification". So, when pharmaceutical enterprises are more active in participation, or when the probability that citizens feedback true evaluation is low, new media are more inclined to verify the evaluation from citizens to ensure the authenticity of reports.

According to proposition 4, the evolutionary trend of new media's strategy is shown in Figure 5.

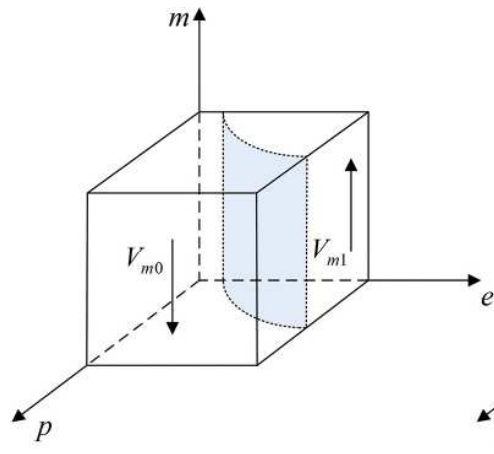

$p=p_{3}$

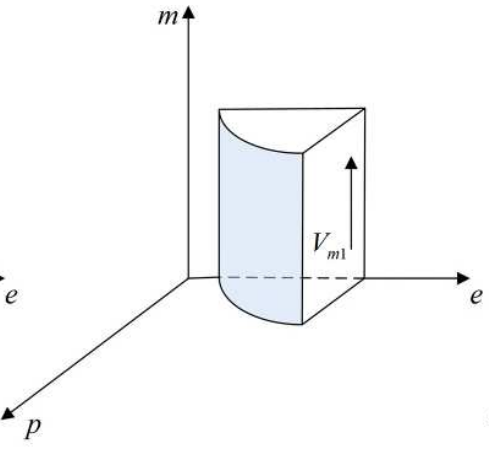

$p<p_{3}$

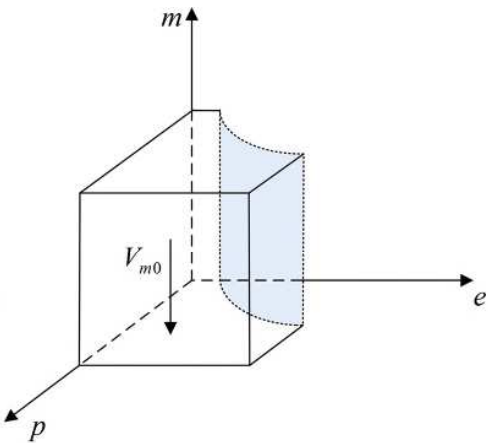

$p>p_{3}$

(Figure 5 The evolutionary trend of new media's strategy)

From Figure 5, the probability that new media choose "Report after verification" equals the volume $V_{m 1}$ and the probability that new media choose "Report without verification" equals the volume $V_{m 0}$.

$$
\begin{aligned}
& V_{m 1}=\int_{0}^{1} \int_{\frac{C_{m h}-C_{m l}}{R_{m}+T_{m}+F_{m}}}^{1} 1-\frac{C_{m h}-C_{m l}}{e\left(R_{m}+T_{m}+F_{m}\right)} d e d m=1-\frac{C_{m h}-C_{m l}}{R_{m}+T_{m}+F_{m}}+\frac{C_{m h}-C_{m l}}{R_{m}+T_{m}+F_{m}} \ln \frac{C_{m h}-C_{m l}}{R_{m}+T_{m}+F_{m}} \\
& V_{m 0}=1-V_{m 1}=\frac{C_{m h}-C_{m l}}{R_{m}+T_{m}+F_{m}}-\frac{C_{m h}-C_{m l}}{R_{m}+T_{m}+F_{m}} \ln \frac{C_{m h}-C_{m l}}{R_{m}+T_{m}+F_{m}}
\end{aligned}
$$

Corollary 4.1 The probability of new media choosing "Report after verification" is negatively correlated with the extra cost of verification, and positively correlated with the pageview revenue from verifying false evaluation.

Proof Take the first-order derivative of $V_{m 1}$ with respect to $\left(C_{m h}-C_{m l}\right)$ and $R_{m}$, and we can get

$$
\begin{aligned}
& \frac{\partial V_{m 1}}{\partial\left(C_{m h}-C_{m l}\right)}=-\frac{1}{R_{m}+T_{m}+F_{m}} \ln \frac{R_{m}+T_{m}+F_{m}}{C_{m h}-C_{m l}}<0 \\
& \frac{\partial V_{m 1}}{\partial R_{m}}=\frac{C_{m h}-C_{m l}}{\left(R_{m}+T_{m}+F_{m}\right)^{2}} \ln \frac{R_{m}+T_{m}+F_{m}}{C_{m h}-C_{m l}}>0
\end{aligned}
$$

Corollary 4.1 indicates that reducing the cost of new media verifying citizens' evaluation or increasing the pageview revenue of verifying evaluation can improve 
the probability of new media choosing "Report after verification".

Corollary 4.2 The probability of new media choosing "Report without verification" is negatively correlated with the loss of pageview value and punishment.

Proof Take the first-order derivative of $V_{m 0}$ with respect to $T_{m}$ and $F_{m}$, and we can get

$$
\begin{aligned}
& \frac{\partial V_{m 0}}{\partial T_{m}}=-\frac{C_{m h}-C_{m l}}{\left(R_{m}+T_{m}+F_{m}\right)^{2}} \ln \frac{R_{m}+T_{m}+F_{m}}{C_{m h}-C_{m l}}<0 \\
& \frac{\partial V_{m 0}}{\partial F_{m}}=-\frac{C_{m h}-C_{m l}}{\left(R_{m}+T_{m}+F_{m}\right)^{2}} \ln \frac{R_{m}+T_{m}+F_{m}}{C_{m h}-C_{m l}}<0
\end{aligned}
$$

Corollary 4.2 indicates that when the new media choose to report the citizens' evaluation without verification, if the evaluation is false, with the loss of pageview value and punishment increasing, they will be more inclined to choose "Report after verification".

Corollary 4.3 When the new media report without verification and cause false report, if the punishment that they should bear satisfies $F_{m}>F_{m 3}$, the new media will choose "Report after verification". But if $F_{m}<F_{m 3}$, the new media will choose "Report without verification". The threshold is $F_{m 3}=\left(C_{m h}-C_{m l}\right) / e(1-p)-R_{m}-T_{m}$.

Proof According to proposition 4, when $K(e, p)=0$, we can get $F_{m 3}=\left(C_{m h}-C_{m l}\right) / e(1-p)-R_{m}-T_{m}$. Take the first-order derivative of $K(e, p)$ with respect to $F_{m}$, and get $\partial K(e, p) / \partial F_{m}>0$. So, $K(e, p)$ is an increasing function of $F_{m}$. When $F_{m}>F_{m 3}$, there are $K(e, p)>0$ and $\left.F^{\prime}(m)\right|_{m=1}<0$. When $F_{m}<F_{m 3}$, there are $K(e, p)<0$ and $\left.F^{\prime}(m)\right|_{m=0}<0$.

Corollary 4.3 indicates that when the new media report without verification and cause false report, if the punishment $F_{m}$ is greater than the threshold $F_{m 3}$, the new media will choose "Report after verification". If $F_{m}$ is less than $F_{m 3}$, the new media will choose "Report without verification". Therefore, in order to exert the restrictive effect of new media on the false evaluation and curb the spread of rumor, the government department should increase the punishment to new media for rumor spreading, and avoid decrease the enthusiasm of pharmaceutical enterprises to participate in emergency management.

\section{Analysis of Stability Equilibrium Points}

According to the Lyapunov First Method, if all the eigenvalues of the Jacobian 
matrix are negative, the equilibrium point is an evolutionary stable strategy (ESS); if the eigenvalues of the Jacobian matrix have at least one positive number, the equilibrium point is an unstable point; if the Jacobian matrix's eigenvalues are all negative except zero, the equilibrium point is in a critical state, and the stability cannot be determined by the eigenvalue symbol. Therefore, we analyze the stability of 16 pure strategy Nash equilibrium points.

According to the replicator dynamic equations, the Jacobi matrix of the dynamic system is

$$
J=\left[\begin{array}{llll}
\partial F(g) / \partial g & \partial F(g) / \partial e & \partial F(g) / \partial p & \partial F(g) / \partial m \\
\partial F(e) / \partial g & \partial F(e) / \partial e & \partial F(e) / \partial p & \partial F(e) / \partial m \\
\partial F(p) / \partial g & \partial F(p) / \partial e & \partial F(p) / \partial p & \partial F(p) / \partial m \\
\partial F(m) / \partial g & \partial F(m) / \partial e & \partial F(m) / \partial p & \partial F(m) / \partial m
\end{array}\right]
$$

\subsection{Stability Analysis when the citizens make true evaluation}

When the citizens' stable strategy is "Evaluate truly", i.e., $V_{p}>C_{p t}-C_{p f}$ is satisfied. Substituting the pure strategy equilibrium points into the Jacobi matrix, we can get the eigenvalues, as shown in Table 3.

Table 3 Stability Analysis when the citizens make true evaluation

\begin{tabular}{|c|c|c|c|}
\hline $\begin{array}{l}\text { Equilibrium } \\
\text { point }\end{array}$ & Eigenvalues $\lambda_{1}, \lambda_{2}, \lambda_{3}, \lambda_{4}$ & Sign & Stability \\
\hline$(0,0,1,0)$ & $\begin{array}{c}M_{g}-\Delta C_{g}-M_{e}+F_{e}+F_{g}, R_{e}+C_{e l}-C_{e h}+L_{e} \\
-\left(V_{p}-C_{p t}+C_{p f}\right), C_{m l}-C_{m h}\end{array}$ & $(\times, \times,-,-)$ & Unstable \\
\hline$(1,0,1,0)$ & $\begin{array}{c}-M_{g}+\Delta C_{g}+M_{e}-F_{e}-F_{g}, R_{e}+C_{e l}-C_{e h}+F_{e}+L_{e} \\
-\left(V_{p}-C_{p t}+C_{p f}\right), C_{m l}-C_{m h}\end{array}$ & $(\times, \times,-,-)$ & $\begin{array}{l}\text { When condition } 1 \\
\text { is satisfied, it is ESS }\end{array}$ \\
\hline$(0,1,1,0)$ & $\begin{array}{c}M_{g}-\Delta C_{g}-M_{e},-R_{e}-C_{e l}+C_{e h}-L_{e} \\
-\left(V_{p}-C_{p t}+C_{p f}+F_{p}\right), C_{m l}-C_{m h}\end{array}$ & $(-, \times,-,-)$ & $\begin{array}{l}\text { When condition (2) } \\
\text { is satisfied, it is ESS }\end{array}$ \\
\hline$(0,0,1,1)$ & $\begin{array}{c}M_{g}-\Delta C_{g}-M_{e}+F_{e}+F_{g}, R_{e}+C_{e l}-C_{e h}+L_{e} \\
-\left(V_{p}-C_{p t}+C_{p f}\right), C_{m h}-C_{m l}\end{array}$ & $(\times, \times,-,+)$ & Unstable \\
\hline$(1,1,1,0)$ & $\begin{array}{c}-M_{g}+\Delta C_{g}+M_{e},-R_{e}-C_{e l}+C_{e h}-F_{e}-L_{e} \\
-\left(V_{p}-C_{p t}+C_{p f}+F_{p}\right), C_{m l}-C_{m h}\end{array}$ & $(+, \times,-,-)$ & Unstable \\
\hline$(1,0,1,1)$ & $\begin{array}{c}-M_{g}+\Delta C_{g}+M_{e}-F_{e}-F_{g}, R_{e}+C_{e l}-C_{e h}+F_{e}+L_{e} \\
-\left(V_{p}-C_{p t}+C_{p f}\right), C_{m h}-C_{m l}\end{array}$ & $(\times, \times,-,+)$ & Unstable \\
\hline$(0,1,1,1)$ & $\begin{array}{c}M_{g}-\Delta C_{g}-M_{e},-R_{e}-C_{e l}+C_{e h}-L_{e} \\
-\left(V_{p}-C_{p t}+C_{p f}+U_{p}+F_{p}\right), C_{m h}-C_{m l}\end{array}$ & $(-, \times,-,+)$ & Unstable \\
\hline$(1,1,1,1)$ & $\begin{array}{c}-M_{g}+\Delta C_{g}+M_{e},-R_{e}-C_{e l}+C_{e h}-F_{e}-L_{e} \\
-\left(V_{p}-C_{p t}+C_{p f}+U_{p}+F_{p}\right), C_{m h}-C_{m l}\end{array}$ & $(+, \times,-,+)$ & Unstable \\
\hline
\end{tabular}

Note. $\times$ means that the sign is uncertain

Condition(1). $\Delta C_{g}+M_{e}<M_{g}+F_{e}+F_{g}, \quad R_{e}+F_{e}+L_{e}<C_{e h}-C_{e l}$. Condition(2). $R_{e}+L_{e}>C_{e h}-C_{e l}$ 
From Table 3, when the additional supervision cost and the subsidy to pharmaceutical enterprises are less than the subsidy to the government department as well as the punishment imposed on the pharmaceutical enterprises and the government department, and when the additional cost of pharmaceutical enterprises participating actively is greater than their additional sales revenue, the loss and punishment, the equilibrium point $(1,0,1,0)$ is ESS. When the additional sales revenue and the loss is greater than the additional cost, the equilibrium point $(0,1,1,0)$ is ESS.

Therefore, when pharmaceutical enterprises passively participate in the emergency management, if the government department doesn't strictly implement the emergency management system will be much punished by the superior government, the government department will strictly implement and play a regulatory role on pharmaceutical enterprises. If the loss (such as reputation decline, customer loss, etc.) caused by the citizens' true evaluation is large, the citizens can play a supervisory role on the pharmaceutical enterprises, and promote "Participate actively" to become the stable strategy of pharmaceutical enterprises.

\subsection{Stability Analysis when the citizens make false evaluation}

When the citizens' stable strategy is "Evaluate falsely", i.e., $V_{p}+U_{p}+F_{p}<C_{p t}-C_{p f}$ is satisfied. Substituting the pure strategy equilibrium points into the Jacobi matrix, we can get the eigenvalues, as shown in Table 4.

Table 4 Stability Analysis when the citizens make false evaluation

\begin{tabular}{|c|c|c|c|}
\hline $\begin{array}{l}\text { Equilibrium } \\
\text { point }\end{array}$ & Eigenvalues $\lambda_{1}, \lambda_{2}, \lambda_{3}, \lambda_{4}$ & Sign & Stability \\
\hline$(0,0,0,0)$ & $\begin{array}{c}M_{g}-\Delta C_{g}-M_{e}+F_{e}, R_{e}+C_{e l}-C_{e h}-D_{e} \\
V_{p}-C_{p t}+C_{p f}, C_{m l}-C_{m h}\end{array}$ & $(-, \times,-,-)$ & $\begin{array}{l}\text { When condition (3) } \\
\text { is satisfied, it is ESS }\end{array}$ \\
\hline$(1,0,0,0)$ & $\begin{array}{c}-\left(M_{g}-\Delta C_{g}-M_{e}+F_{e}\right), R_{e}+C_{e l}-C_{e h}-D_{e}+F_{e} \\
V_{p}-C_{p t}+C_{p f}, C_{m l}-C_{m h}\end{array}$ & $(+, \times,-,-)$ & Unstable \\
\hline$(0,1,0,0)$ & $\begin{array}{c}M_{g}-\Delta C_{g}-M_{e},-R_{e}-C_{e l}+C_{e h}+D_{e} \\
V_{p}-C_{p t}+C_{p f}+F_{p}, C_{m l}-C_{m h}+R_{m}+T_{m}+F_{m}\end{array}$ & $(-, \times,-,+)$ & Unstable \\
\hline$(0,0,0,1)$ & $\begin{array}{c}M_{g}-\Delta C_{g}-M_{e}+F_{e}, R_{e}+C_{e l}-C_{e h} \\
V_{p}-C_{p t}+C_{p f}, C_{m h}-C_{m l}\end{array}$ & $(-, \times,-,+)$ & Unstable \\
\hline$(1,1,0,0)$ & $\begin{array}{c}-M_{g}+\Delta C_{g}+M_{e},-R_{e}-C_{e l}+C_{e h}+D_{e}-F_{e}, \\
V_{p}-C_{p t}+C_{p f}+F_{p}, C_{m l}-C_{m h}+R_{m}+T_{m}+F_{m}\end{array}$ & $(+, \times,-,+)$ & Unstable \\
\hline$(1,0,0,1)$ & $\begin{array}{c}-M_{g}+\Delta C_{g}+M_{e}-F_{e}, R_{e}+C_{e l}-C_{e h}+F_{e} \\
V_{p}-C_{p t}+C_{p f}, C_{m h}-C_{m l}\end{array}$ & $(+, \times,-,+)$ & Unstable \\
\hline$(0,1,0,1)$ & $M_{g}-\Delta C_{g}-M_{e},-R_{e}-C_{e l}+C_{e h}$ & $(-, \times,-,-)$ & When condition (4) \\
\hline
\end{tabular}




\begin{tabular}{ccc}
\hline & $V_{p}-C_{p t}+C_{p f}+U_{p}+F_{p},-C_{m l}+C_{m h}-R_{m}-T_{m}-F_{m}$ & is satisfied, it is ESS \\
& $-M_{g}+\Delta C_{g}+M_{e},-C_{m l}+C_{m h}-R_{m}-T_{m}-F_{m}$, & \\
$(1,1,0,1)$ & $(+, \times,-,-)$ & Unstable \\
& $V_{p}-C_{p t}+C_{p f}+U_{p}+F_{p},-C_{m l}+C_{m h}-R_{m}-T_{m}-F_{m}$ & \\
\hline
\end{tabular}

Note. $\times$ means that the sign is uncertain

Condition(3). $C_{e h}-C_{e l}+D_{e}>R_{e}$. Condition(4). $R_{e}>C_{e h}-C_{e l}$

From Table 4, when the additional cost of pharmaceutical enterprises participating actively and the loss caused by false evaluation is greater than the additional sales revenue, the equilibrium point $(0,0,0,0)$ is ESS. When the additional sales revenue is greater than the additional cost of pharmaceutical enterprises participating actively, the equilibrium point $(1,1,0,1)$ is ESS.

Therefore, to avoid "Participate passively" becoming the stable strategy of pharmaceutical enterprises, the cost of active participation should be reduced and the additional sales revenue should be increased. When the cost of active participation is low and the additional sales revenue is high, the stable strategy of pharmaceutical enterprises is "Participate actively". At this time, the new media will also verify the evaluation to avoid being held accountable by pharmaceutical enterprises.

\section{Simulation Analysis}

In order to reflect the impact of various parameters on the strategy choices of the government department, pharmaceutical enterprises, citizens and new media in public health events emergency management, we use Matlab $2020 b$ to conduct the simulation analysis.

When the government department strictly implements the emergency management system, the additional supervision cost is $\Delta C_{g}=4.5$, the subsidy from the superior government is $M_{g}=5.0$, the subsidy to pharmaceutical enterprises is $M_{e}=2.0$, the punishment imposed on pharmaceutical enterprises is $M_{e}=2.0$, and When the government department doesn't strictly implement, the punishment that it should bear is $F_{g}=4.0$. When the pharmaceutical enterprises actively participate in the emergency management, the additional sales revenue is $R_{e}=2.5$, the additional cost is $\Delta C_{e}=4.0$. When the citizens make true evaluation, the reward that they obtain from new media is $V_{p}=1.0$ and the cost is $C_{p t}=2.5$. If the pharmaceutical enterprises passively participate in the emergency management, the true evaluation will bring them the loss $L_{e}=3.0$. When the citizens make false evaluation, the cost is $C_{p f}=0.5$, and they will bear the punishment $F_{p}=1.0$. When new media report after 
verification, the additional cost is $\Delta C_{m}=2.0$, the pageview revenue is $R_{m}=2.5$ and the utility loss of citizens is $U_{p}=1.0$. When new media report the false evaluation, the pharmaceutical enterprises' reputation loss is $D_{e}=2.0$, the new media's loss of pageview value is $T_{m}=2.5$ and the punishment that new media should bear is $F_{m}=3.0$.

\subsection{The influence of the probability that the new media report after verification}

The probability that the new media report after verification is $m=\{0.0,0.2,0.5\}$. The strategy evolution process and result of the government department, pharmaceutical enterprises and citizens are shown in Figure 6.
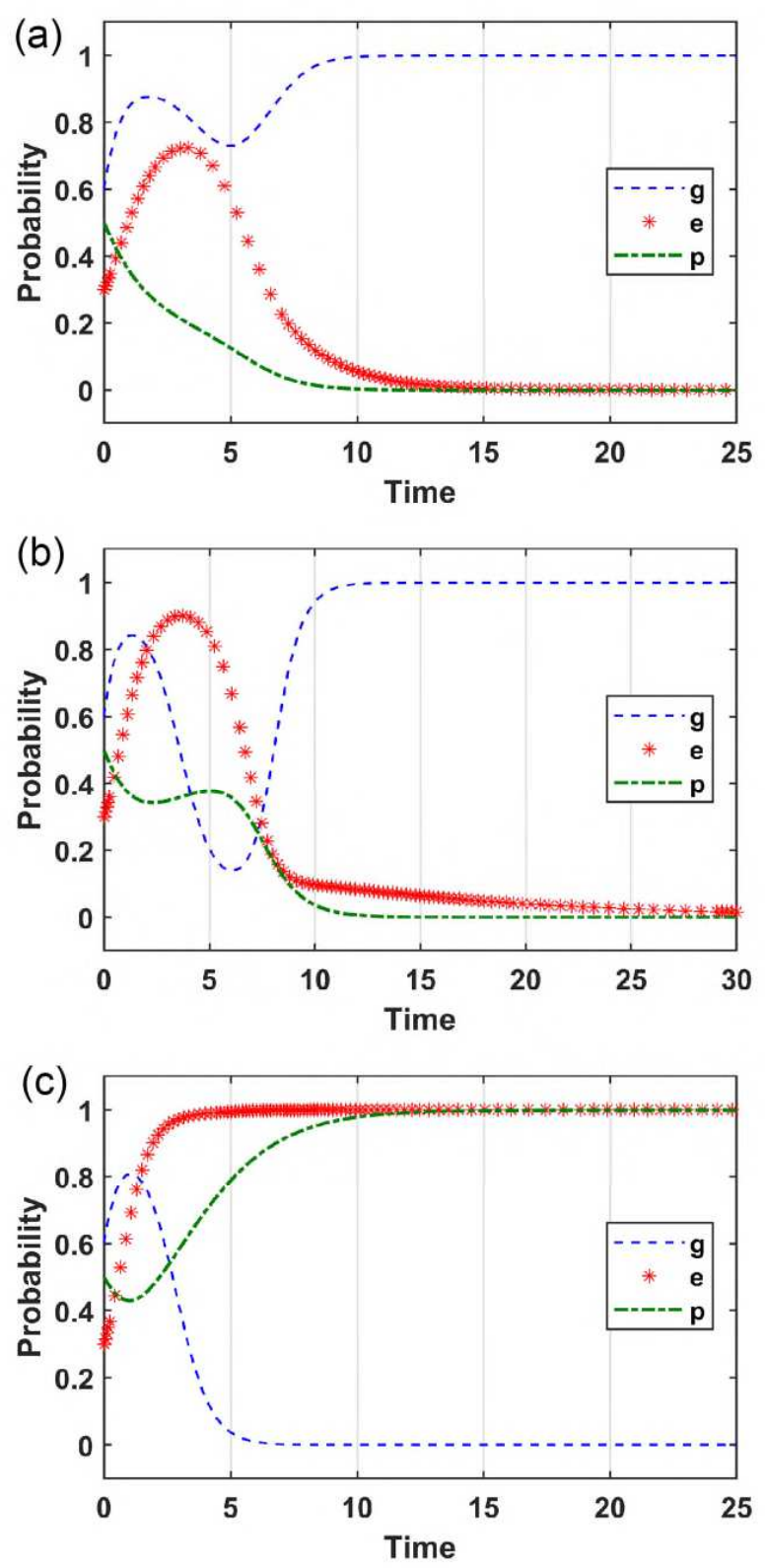

(Figure 6 The influence of the probability that the new media report after verification) 
From Figure 6, when the probability that new media report after verification is low, the probability that the citizens make false evaluation is high, which will decrease the enthusiasm of pharmaceutical enterprises to participate in emergency management, and the government department will choose to strictly implement the emergency management system to supervise the behavior of pharmaceutical enterprises. With the increase of the probability that new media report after verification, the citizens' stability strategy is changed to "Evaluate truly", and the pharmaceutical enterprises' stability strategy is changed to "Participate actively". At this time, the government department will choose the strategy of "Not implement strictly".

\subsection{The influence of the citizen participation}

The probability that citizens make true evaluation is $p=\{0.2,0.4,0.8\}$. The strategy evolution process and result of the government department, pharmaceutical enterprises and new media are shown in Figure 7. 

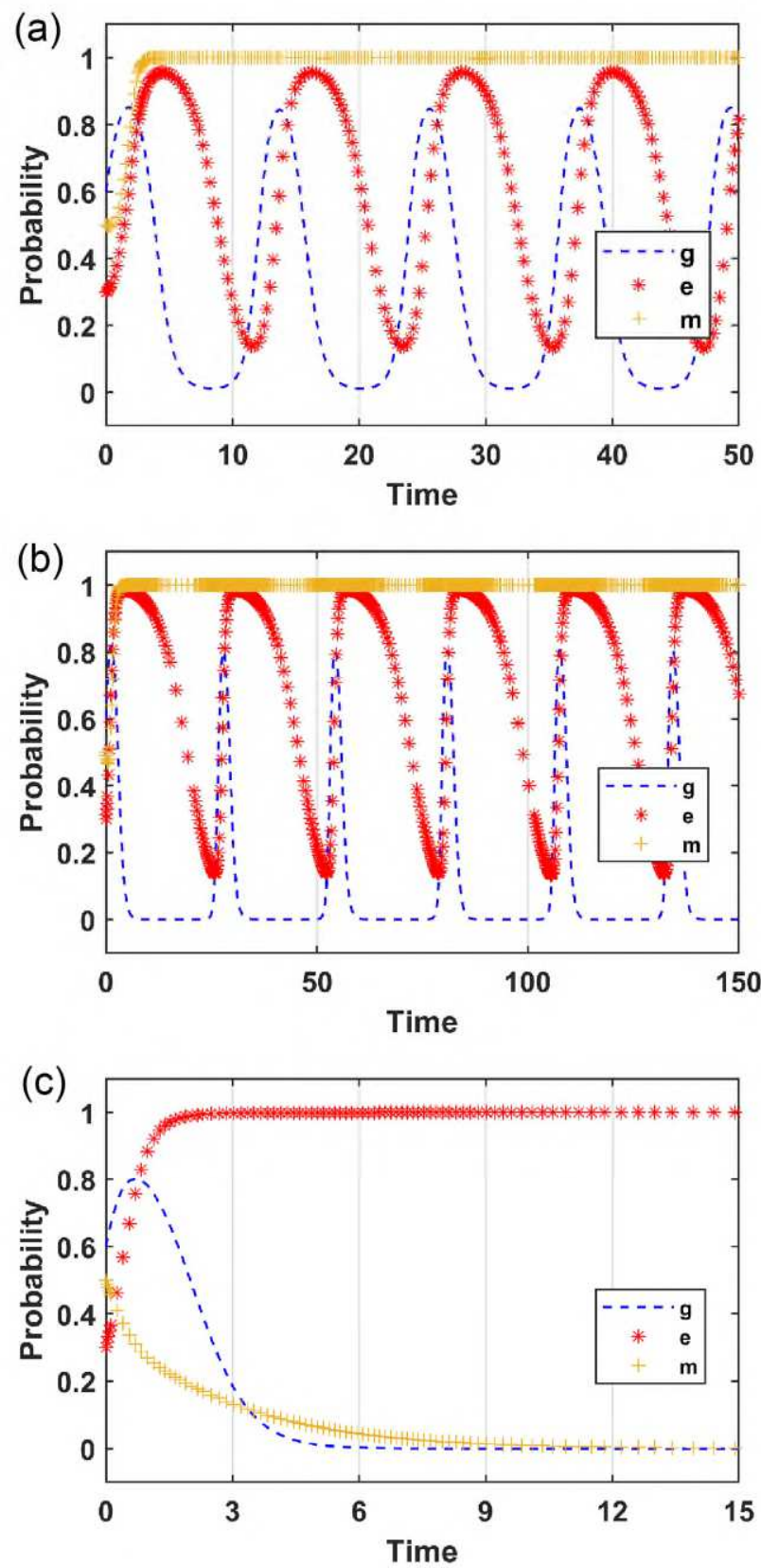

(Figure 7 The influence of the probability that citizens make true evaluation)

From Figure 7, when the citizens tend to make false evaluation, the stable strategy of new media is "Report after verification", and the strategy choice of pharmaceutical enterprises is constantly adjusted with the strategy choice of government department. With the increase of the probability that the citizens make true evaluation, the stability strategy of pharmaceutical enterprises is "Participate actively". At this time, the citizens play the supervisory role for pharmaceutical enterprises.

When the citizens make false evaluation, the pharmaceutical enterprises' reputation loss is $D_{e}=0.5$. When the citizens make true evaluation, if pharmaceutical 
enterprises passively participate in the emergency management, the pharmaceutical enterprises' loss is $L_{e}=\{0.5,1.0,3.0\}$. The strategy evolution process and result of the government department, pharmaceutical enterprises, citizens and new media are shown in Figure 8.
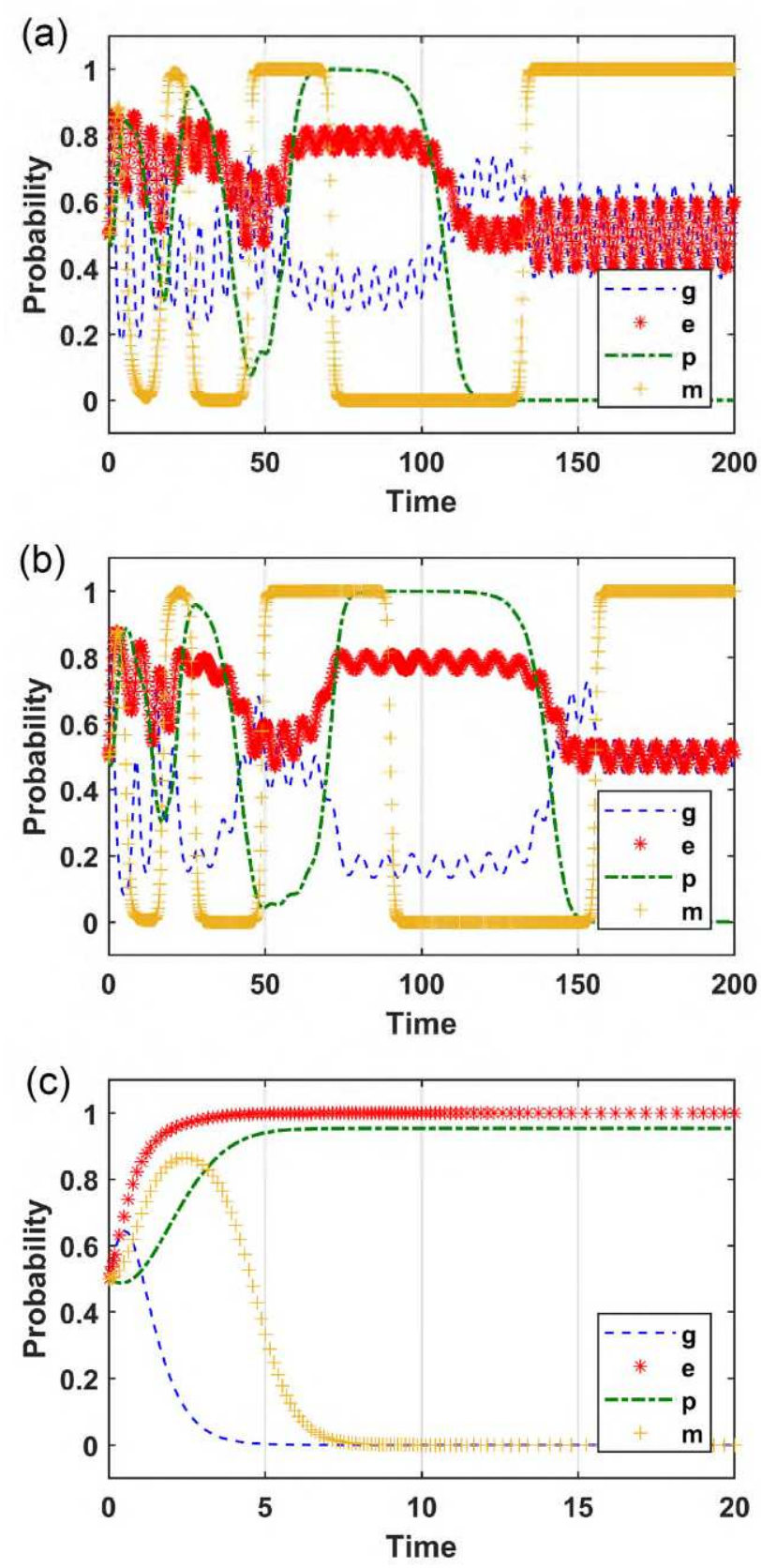

(Figure 8 The influence of the pharmaceutical enterprises' loss)

From Figure 8, when pharmaceutical enterprises passively participate in emergency management, with the loss caused by the true evaluation of the citizens increasing, the strategy choice of pharmaceutical enterprises changes from instability to "Participate actively", and the strategy choice of the citizens also changes from instability to "Evaluate truly". In other words, when the true evaluation has a great 
impact on the pharmaceutical enterprises, the citizens will be more inclined to play their own supervisory role.

When the pharmaceutical enterprises passively participate in the emergency management, if the citizens make true evaluation, the loss of pharmaceutical enterprises is $L_{e}=0.5$. When the pharmaceutical enterprises actively participate in the emergency management, if the citizens make false evaluation, the pharmaceutical enterprises' reputation loss is $D_{e}=\{0.0,0.5,1.0\}$. The strategy evolution process and result of the government department, pharmaceutical enterprises, citizens and new media are shown in Figure 9.
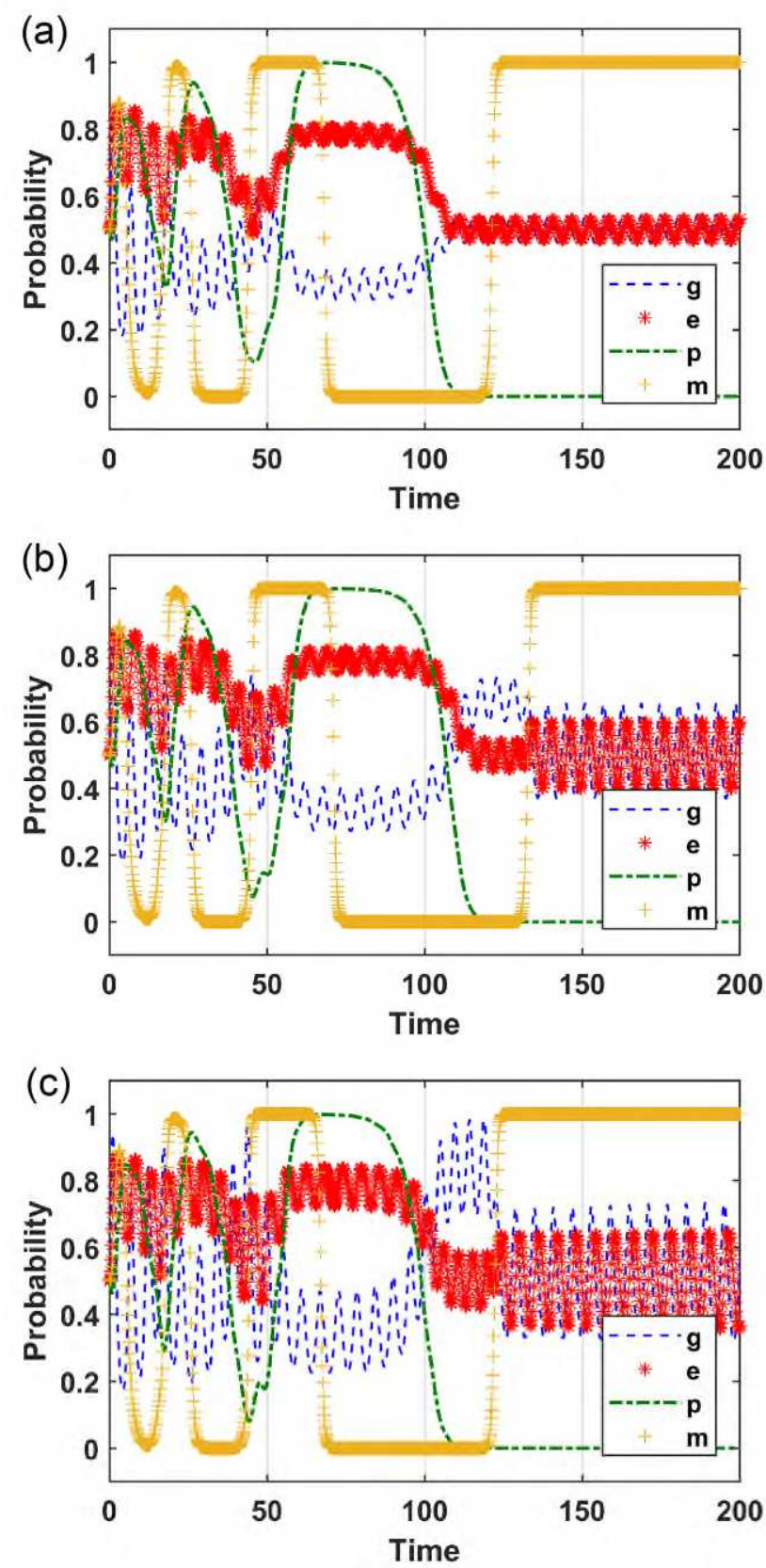

(Figure 9 The influence of the pharmaceutical enterprises' reputation loss) 
From Figure 9, when pharmaceutical enterprises actively participate in emergency management, with the reputation loss caused by false evaluation increasing, the amplitude of the probability of pharmaceutical enterprises' strategy choice will increase. At this time, the strategy choice of pharmaceutical enterprises will fluctuate with the adjustment of the strategy choice of government department. In addition, when the citizens' false evaluation causes more reputation loss to pharmaceutical enterprises, the government department needs to improve the probability of "Implement strictly" in order to ensure pharmaceutical enterprises actively participate in emergency management.

\subsection{The influence of the punishment}

The probability that new media report after verification is $m=0.5$. When the government department doesn't implement strictly, the punishment is $F_{g}=\{0.0,2.5,4.0\}$. When the pharmaceutical enterprises passively participate, the punishment is $F_{e}=\{0.0,2.0,3.0\}$. When the citizens make false evaluation, the punishment is $F_{p}=\{0.0,0.4,1.0\}$. The strategy evolution process and result of the government department, pharmaceutical enterprises, and citizens are shown in Figure 10.

(a)

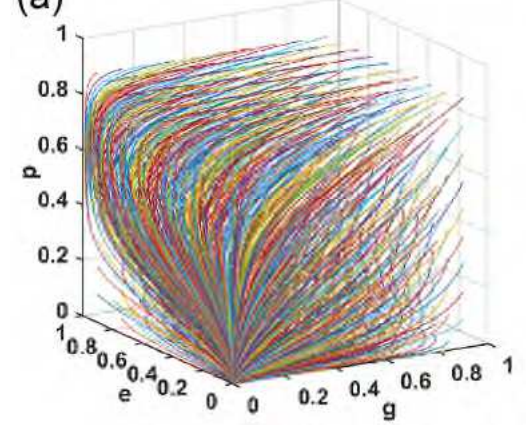

(b)

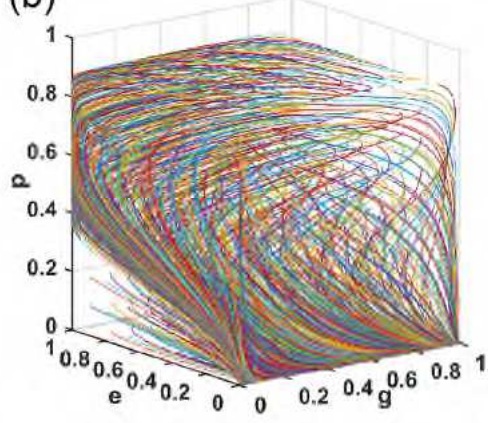

(c)

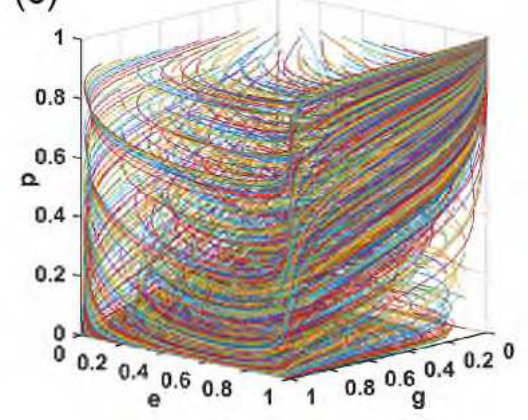

(Figure 10 The influence of the punishment)

From Figure 10, when the government department doesn't strictly implement the emergency system, pharmaceutical enterprises passively participate in the emergency management, and citizens make false evaluation, if there is no punishment for them, the evolutionary stable equilibrium point is $(0,0,0)$. With the increase of punishment when government department doesn't strictly implement, pharmaceutical enterprises passively participate, and the citizens make false evaluation, the equilibrium point evolves to $(1,0,0)$, and then to $(0,1,1)$. As a result, the punishment has a restrictive effect on the strategy choices of government department, pharmaceutical enterprises 
and the citizens.

\section{Discussion}

In this paper, we construct an evolutionary game model involving four players, analyze the evolutionary stability and solve the stable equilibrium points using the Lyapunov first method. In addition, we conduct the simulation analysis with Matlab 2020b. Then we can get the following discussion.

First of all, when the probability of pharmaceutical enterprises actively participating in emergency management is low or the probability of citizens making true evaluation is high, the stable strategy of government department is to strictly implement the emergency management system.

Secondly, with the probability of government department strictly implementing the emergency management system, the probability of citizens making true evaluation and the probability of new media reporting after verification increasing, the probability that pharmaceutical enterprises choose to actively participate in emergency management will increase.

Thirdly, when the probability of pharmaceutical enterprises actively participating in emergency management increases, the citizens' stable strategy changes from false evaluation to true evaluation. When the probability of new media reporting after verification is high, the citizens' stable strategy is true evaluation.

What's more, as the probability of pharmaceutical enterprises actively participating in emergency management increases, the probability of new media reporting after verification increases. When the probability of citizens making true evaluation is low, the stable strategy of new media is to report after verification.

\section{Conclusions}

From the discussion, we can reach the following conclusions.

Firstly, when pharmaceutical enterprises are less active in participating in emergency management, government department will play a regulatory role on them. In addition, citizen participation in emergency management through true evaluation can play the supervisory role on government department.

Secondly, citizens' true evaluation on pharmaceutical enterprises can exert the supervision role of citizens, but the false evaluation will decrease the enthusiasm of pharmaceutical enterprises to participate in emergency management. So, government department should formulate policies including rewards and punishment to encourage 
the citizens to make true evaluation and restrict them to make false evaluation.

Thirdly, when pharmaceutical enterprises actively participate in emergency management, the citizens are more inclined to make true evaluation. Besides, new media's verification can improve the probability of citizens making true evaluation and the probability of pharmaceutical enterprises actively participating.

In addition, the greater the punishment imposed on new media for false report, the greater the probability of new media reporting after verification. Therefore, when new media release false report, government department should strengthen the punishment to improve the probability of new media report after verification.

This paper constructs an evolutionary game model, and studies the influence of new media and citizen participation on the strategy choices of government department and pharmaceutical enterprises. However, the game model is completely informational and one-stage under the condition of bounded rationality and without considering the game sequence. Therefore, in the future research, we will build a multi-stage, repeated and dynamic game model with multi-agent participation under the condition of incomplete information.

\section{Compliance with Ethical Standards}

\section{Disclosure of potential conflicts of interest}

Author Lilong Zhu declares that he has no conflict of interest. Author Bingjie Lu declares that she has no conflict of interest.

\section{Funding details}

This study was funded by the National Social Science Foundation of China under grant No.20BGL272 and No.21ZDA024.

\section{Ethical approval}

This article does not contain any studies with human participants or animals performed by any of the authors.

\section{Informed Consent}

Informed consent was obtained from all individual participants included in the study.

\section{Authorship contributions}


Bingjie Lu (first author) write the manuscript and make the simulation analysis, Lilong Zhu (corresponding author) design the model and revise the manuscript.

\section{Statistical data}

All the data is available and within the manuscript, no supplement materials data.

\section{Acknowledgments}

The authors are grateful to the referees for their valuable comments and their helps on how to improve the quality of our paper.

\section{References}

Bao Y.P., Sun Y.K., Meng S.Q., et al. 2019-nCoV epidemic: address mental health care to empower society. Lancet, 2020, 395: 37-38.

Blevins D.P., Ragozzino R. On Social Media and the Formation of Organizational Reputation: How Social Media Are Increasing Cohesion Between Organizational Reputation and Traditional Media for Stakeholders. Academy of Management Review, 2019, 44(1): 219-222.

Brauner J.M., Mindermann S., Sharma M., et al. Inferring the effectiveness of government interventions against COVID-19. Science, 2021, 371(6531): 802-809.

Chinazzi M., Davis J.T., Ajelli M., et al. The effect of travel restrictions on the spread of the 2019 novel coronavirus (COVID-19) outbreak. Science, 2020, 368(6489): $395-400$.

Comfort L.K., Kapucu N., Ko K.L., et al. Crisis Decision-Making on a Global Scale: Transition from Cognition to Collective Action under Threat of COVID-19. Public Administration Review, 2020, 80(4): 616-622.

Elbanna A., Bunker D., Levine L., et al. Emergency management in the changing world of social media: Framing the research agenda with the stakeholders through engaged scholarship. International Journal of Information Management, 2019, 47: 112-120.

Etter M., Ravasi D., Colleoni E. Social Media And The Formation Of Organizational Reputation. Academy of Management Review, 2019, 44(1): 28-52.

Flaxman S., Mishra S., Gandy A., et al. Estimating the effects of non-pharmaceutical interventions on COVID-19 in Europe. Nature, 2020, 584(7820): 257-261.

Gao Q., Bao L.L., Mao H.Y., et al. Development of an inactivated vaccine candidate for SARS-CoV-2. Science, 2020, 369(6499): 77-80. 
Hsiang S., Allen D., Annan-Phan S., et al. The effect of large-scale anti-contagion policies on the COVID-19 pandemic. Nature, 2020, 584(7820): 262-267.

Kavota J.K., Kamdjoug J.R.K., Wamba S.F. Social media and disaster management: Case of the north and south Kivu regions in the Democratic Republic of the Congo. International Journal of Information Management, 2020, 52.

Kraemer Moritz U.G., Yang C.H., Gutierrez B., et al. The effect of human mobility and control measures on the COVID-19 epidemic in China. Science, 2020, 368(6490): 493-497.

Krammer F. SARS-CoV-2 vaccines in development. Nature, 2020, 586(7830): $516-527$.

Lee J., Kim S. Citizens' e-participation on agenda setting in local governance: Do individual social capital and e-participation management matter?. Public Management Review, 2018, 20(6):873-895.

Liao Q.Y., Yuan J.H., Dong M.H., et al. Public Engagement and Government Responsiveness in the Communications About COVID-19 During the Early Epidemic Stage in China: Infodemiology Study on Social Media Data. Journal of Medical Internet Research, 2020, 22(5).

Lu X., Horn A.L., Su J.H., et al. A Universal Measure for Network Traceability. Omega, 2019, 87: 191-204.

Lu Z.Y., Huang P.F., Liu Z.X. Predictive Approach for Sensorless Bimanual Teleoperation Under Random Time Delays With Adaptive Fuzzy Control. IEEE Transactions on Industrial Electronics, 2018, 65(3):2439-2448.

Maon F., Swaen V., De Roeck K. Coporate branding and corporate social responsibility: Toward a multi-stakeholder interpretive perspective. Journal of Business Research, 2021, 126(5): 64-77.

Moon M.J. Fighting COVID-19 with Agility, Transparency, and Participation: Wicked Policy Problems and New Governance Challenges. Public Administration Review, 2020, 80(4): 651-656.

Rodell J.B., Sabey T.B., Rogers K.M. "Tapping" Into Goodwill: Enhancing Corporate Reputation Through Customer Volunteering. Academy of Management Journal, 2020, 63(6): 1714-1738.

Rong J.M., Zhu L.L. Cleaner Production Quality Regulation Strategy of Pharmaceutical with Collusive Behavior and Patient Feedback. Complexity, 2020, 2020. 
Sjoberg F.M., Mellon J., Peixoto T. The Effect of Bureaucratic Responsiveness on Citizen Participation. Public Administration Review, 2017, 77(3): 340-351.

Syed R. Enterprise reputation threats on social media: A case of data breach framing. Journal of Strategic Information Systems, 2019, 28(3): 257-274.

Tian H.Y., Liu, Y.H., Li Y.D., et al. An investigation of transmission control measures during the first 50 days of the COVID-19 epidemic in China. Science, 2020, 368(6491): 638-642.

Uzochukwu K., Thomas J.C. Who Engages in the Coproduction of Local Public Services and Why? The Case of Atlanta, Georgia. Public Administration Review, 2018, 78(4): 514-526.

Wei J.C., Ouyang Z., Chen H.P. Well Known or Well Liked? The Effects of Corporate Reputation on Firm Value at the Onset of a Corporate Crisis. Strategic Management Journal, 2017, 38(10): 2103-2120.

Wu J.T., Leung K., Leung G.M. Nowcasting and forecasting the potential domestic and international spread of the 2019-nCoV outbreak originating in Wuhan, China: a modelling study. Lancet, 2020, 395(10225): 689-697.

Yan Z.J., Wang T.M., Chen Y., et al. Knowledge sharing in online health communities: a social exchange theory perspective. Information \& Management, 2016, 53(5): 643-653.

Yong B.B., Shen J., Liu X., et al. An intelligent blockchain-based system for safe vaccine supply and supervision. International Journal of Information Management, 2020, 52.

Zhang F.X., Feeney Mary K. Engaging through technology: the role of administrative culture and mandates. Public Management Review, 2019, 22(10): 1423-1442. 


\section{Figure legends}

Figure 1 The logical relationship of the four-party game model

In Figure 1, we describe the logical relationship between the government department, pharmaceutical enterprises, citizens and new media in the emergency management and supervision of public health events.

Figure 2 The evolutionary trend of government department's strategy

In Figure 2, we describe the evolutionary trend of government department's strategy and the probability of government department's strategy choice changes with the probability of pharmaceutical enterprises' strategy choice.

Figure 3 The evolutionary trend of pharmaceutical enterprises' strategy

In Figure 3, we describe the evolutionary trend of pharmaceutical enterprises' strategy and the probability of pharmaceutical enterprises' strategy choice changes with the probability of citizens' strategy choice.

Figure 4 The evolutionary trend of citizens' strategy

In Figure 4, we describe the evolutionary trend of citizens' strategy and the probability of citizens' strategy choice with the probability of new media's strategy choice.

Figure 5 The evolutionary trend of new media's strategy

In Figure 5, we describe the evolutionary trend of new media's strategy and the probability of new media's strategy choice changes with the probability of citizens' strategy choice.

Figure 6 The influence of the probability that the new media report after verification

In Figure 6, we describe that the strategy evolutionary trend of government department, pharmaceutical enterprises and citizens changes with the probability of new media's strategy choice.

Figure 7. The influence of the probability that citizens make true evaluation

In Figure 7, we describe that the strategy evolutionary trend of government department, pharmaceutical enterprises and new media changes with the probability of citizens' strategy choice.

Figure 8 The influence of the pharmaceutical enterprises' loss

In Figure 8, we describe how the strategy evolutionary trend of government department, pharmaceutical enterprises, citizens and new media changes with the pharmaceutical enterprises' loss increasing.

Figure 9 The influence of the pharmaceutical enterprises' reputation loss

In Figure 9, we describe how the strategy evolutionary trend of government department, pharmaceutical enterprises, citizens and new media changes with the pharmaceutical enterprises' reputation loss increasing.

Figure 10 The influence of the punishment

In Figure 10, we describe how the strategy evolutionary trend of government department, pharmaceutical enterprises, and citizens changes with the punishment increasing. 